To appear in C. Fabricius-Hansen, E. Lang and C. Maienborn (eds.), Modifying Adjuncts. Series: Interface Explorations. Mouton - de Gruyter. Ms. 2002. [Revision of Partee and Borschev 2000b]

\title{
Genitives, relational nouns, and argument-modifier ambiguity ${ }^{1}$
}

\author{
Barbara H. Partee and Vladimir Borschev \\ partee@linguist.umass.edu, borschev@linguist.umass.edu
}

\begin{abstract}
The argument-modifier distinction is less clear in NPs than in VPs since nouns do not typically take arguments. The clearest cases of arguments in NPs are found in certain kinds of nominalizations which retain some "verbal" properties (Grimshaw 1990). The status of apparent arguments of non-deverbal relational nouns like sister is more controversial.

Genitive constructions like John's teacher, team of John's offer a challenging testing ground for the argument-modifier distinction in NPs, both in English and cross-linguistically. In the analyses of Partee (1983/1997) and Barker (1995), the DP in a genitive phrase (i.e. John in John's) is always an argument of some relation, but the relation does not always come from the head noun. In those split analyses, some genitives are arguments and some are modifiers. By contrast, recent proposals by Jensen and Vikner and by Borschev and Partee analyze all genitives as arguments, a conclusion we no longer support.

In this paper, we explore a range of possible analyses: argument-only, modifier-only, and split analyses, and we consider the kinds of semantic evidence that imply that different analyses are correct for different genitive or possessive constructions in different languages. For English, we argue that a split analysis is correct and we offer some diagnostics for distinguishing arguments from modifiers.
\end{abstract}

\section{The argument-modifier distinction in NPs}

The argument-modifier distinction is less clear in NPs than in VPs since nouns do not typically take arguments. The clearest cases of arguments in NPs are found in some nominalizations (Grimshaw 1990). Non-deverbal relational nouns like sister, mayor, enemy, picture, edge, height in some sense also seem to take arguments. C. L. Baker (1978) proposed a test using English one anaphora whereby one substitutes for N-bar, which obligatorily includes all of a noun's arguments. By that test, to Oslo in (1a) is a modifier, while of Boston in (1b) is an argument. But neither this, nor any other known test, has seemed conclusive and the question of whether and in what sense "true nouns" take arguments remains controversial.

a. The train to Oslo takes longer than the one to Stockholm.

b. *The mayor of Boston has more power than the one of Baltimore.

Genitive $^{2}$ constructions like those in $(2 \mathrm{a}, \mathrm{b})$ offer an interesting test-bed for the argument-modifier distinction in NPs, in English and Russian and, indeed, cross-linguistically.

(2) a. English: John's teacher, John's chair, friend of John's

b. Russian: Mašin ucitel, Mašin stul, drug Maši

Maša-POSS-M.SG. teacher, Maša-Poss-M.SG chair, friend Maša-GEN

'Maša's teacher', 'Maša's chair', 'Maša's friend' 
Many, perhaps all, genitives seem to have some properties of arguments and some of modifiers, yet some seem more like arguments and some more like modifiers. Recent proposals by Jensen and Vikner (1994), Vikner and Jensen (2002), Partee and Borschev (1998), Borschev and Partee $(1999 \mathrm{a}, \mathrm{b})$ analyze all genitives ${ }^{3}$ as arguments, a conclusion we are no longer sure of for English (see Partee and Borschev 2001). While we now doubt that such an analysis is correct for all kinds of genitives in all languages, we do believe that it is correct for some kinds of genitives in some languages. It is not easy to settle the question of whether there is a substantive difference between these two roles of genitives and it may well be the case that all or many genitives play both roles at once.

In both English and Russian there are several constructions which may in some (possibly metaphorical) sense express possession; and in each language there seem to be several different kinds of meanings for constructions which may be considered genitive (genitive morphology in Russian, the morpheme '-s in English). The correlation between constructions and meanings is not transparent.

Major questions about genitive constructions, then, are the following: Are all, some, or no genitives arguments of nouns, and if so, which ones (and how can we tell?), and of what kind, and at what level of analysis? Are some genitives able to get argumental interpretations without actually being arguments in the structural sense of being syntactic complements of the noun and/or of having function-argument structure reflected type-theoretically?

In this paper, we examine semantic aspects relating to the question of whether all genitives can and should be given a uniform analysis, or whether we can find a satisfying way of accommodating a split analysis, while remaining as neutral as possible throughout on the syntactic aspects of the question.

\section{Genitives and related constructions: The challenge}

The terminology surrounding "possessives" and "genitives" is confusing, since the correspondences among morphological forms, syntactic positions, grammatical relations, and semantic interpretations are complex and subject to debate. Further, there is much variation crosslinguistically. For clarification, let us distinguish at least the following: ${ }^{4}$
a. Possessive pronouns: E. my, his; R. moj 'my', ego 'his'; E. predicative forms mine, his; postnominal forms of mine, of his.
b. English "Saxon genitives": John's; the postnominal Saxon genitive of John's.
c. English PP with of $+\mathrm{NP}_{\text {Acc }}$.
d. Russian postnominal genitive NP: Mendeleeva 'of Mendeleev', tigra 'of a/the tiger'.
e. Russian prenominal possessive: Mašin dom 'Masha's house'.

Some problems of the semantics of genitives affect all of the constructions listed in (3), while some problems require more fine-grained distinctions to be made. Very similar problems arise in corresponding constructions in many other languages, and related problems arise with the English verb have and its lexical and constructional counterparts in other languages (Bach 1967; Freeze 1992; Landman and Partee 1984; Szabolcsi 1994; Jensen and Vikner 1996; Partee 1999b). The present work concerns the possible need for a distinction between genitives as modifiers and 
genitives as arguments, and the role that predicate possessives may play in resolving that issue. We leave out of discussion the clear modifier genitives that occur in compounds like a boys' club, although Munn (1995) has shown that the line between those and other genitives is not as sharp as had been thought.

Our starting point is the following data from Partee (1983/1997: 464):
a. John's team
b. a team of John's
c. That team is John's.

(5) a. John's brother

b. a brother of John's

c. (\#) That brother is John's.

(6) a. John's favorite movie

b. a favorite movie of John's

c. (\#) That favorite movie is John's.

Informally, a unified interpretation of the genitive phrase "John's", applicable to all cases in (4)(6), is that the genitive phrase always expresses one argument of a relation, for which we will use the descriptive term "genitive relation", following Jensen and Vikner (1994). However, the relation can come from any of three sources: (i) the context, as in (4) ("plays for", "owns", "is a fan of", etc.); this happens when the noun is a plain one-place predicate; (ii) an inherently relational noun like brother; (iii) an inherently relational adjective like favorite.

Following Partee (1983/1997), we initially refer to case (i) as the "free $\boldsymbol{R}$ " reading, and to cases (ii) and (iii) as "inherent $\boldsymbol{R}$ " readings. (In later parts of the paper, the classification will be revised.)

The puzzles include these:

- Can (and should) examples (4a) and (5a) be given a uniform analysis ? If so, how?

- Or does the genitive construction combine differently with plain and relational nouns ? And if so, are these differences predictable from some general principles?

- Should the first case be split into two distinct cases, one being a default preference of the genitive construction itself for a genitive relation in the family of "owns", "possesses", "controls", possibly with a distinct syntactic source from the context-dependent "free $\boldsymbol{R}$ " readings?

- Does the analysis of genitives require that phrasal as well as lexical categories be able to take complements?

The examples in (6) show that argument genitives cannot always simply be analyzed as complements of a lexical noun, since it is the whole N-bar favorite movie that provides the relation of which John is an argument. ${ }^{5}$

The Russian genitive constructions exemplified in (7) present similar challenges, showing a similar range of genitive relations, with a similar range of relational and plain nouns, although there are also differences between English and Russian to account for. 

a. ljubitel' košek lover-NOM.SG cat-GEN.PL 'lover of cats, cat-lover'
b. rost celoveka height-NOM.SG man-GEN.SG 'height of the/a man'
c. nožka stola leg-NOM.SG table-GEN.SG 'leg of the table, table leg'
d. krug syra
e. stakan moloka glass-NOM.sG milk-GEN.SG 'glass of milk' circle-NOM.SG cheese-GEN.SG 'circle (wheel) of cheese'
f. portret Peti
portrait-NOM.SG Petja-GEN 'picture of Petja'
g. sled tigra
track-NOM.SG tiger-GEN.SG 'track of the/a tiger'
h. sobaka doceri
dog-NOM.SG daughter-GEN.SG 'the daughter's dog'
i. nebo Andreja Bolkonskogo sky-NOM.SG Andrej-GEN Bolkonsky-GEN 'Andrej Bolkonsky's sky'

For Russian, the question of whether the examples in (7) all instantiate a single construction is also difficult and is not identical to the corresponding question for English since there is a many-tomany correspondence between the Russian and the English constructions. The uses of the Russian genitive NP cover uses analogous to the English Saxon genitive, to English of $+\mathrm{NP}_{\mathrm{Acc}}$, and, in some cases, to English noun-noun compounds. English Saxon genitives may translate to Russian as genitives, as prenominal possessives, or as denominal adjectives.

At a descriptive level, virtually all authors who have grappled with the semantics of genitive constructions are in agreement that in some cases the genitive NP seems like an argument and in other cases it seems like a modifier. The argument status of at least some genitives is clearest in the case of certain deverbal nouns, those called "Complex Event Nominals" by Grimshaw (1990) and Schoorlemmer (1995), "Derived Nominals" by Babby (1997), and "Process Nominals" by Rappaport (1998).

To clarify our relatively neutral assumed syntax for the first of these constructions, and for Russian postnominal genitives, we give the syntactic structure in (8) below, a linearized form of the schematic phrase structure tree of Borschev and Partee (1999b):

(8) $\left[\begin{array}{lll}\mathrm{N} & \mathrm{N} & \mathrm{NP}_{\text {GEN }}\end{array}\right]$, where $\mathrm{N}$ is a cover term for $\mathrm{N}^{0}$ and non-maximal $\mathrm{N}$-bar $(=\mathrm{CN}$ and $\mathrm{CNP}$ in Montague (1973)), and NP is a cover term for both $\mathrm{N}^{\mathrm{MAX}}$ and DP. 
The semantic question is: Do the genitive constructions ${ }_{\mathrm{N}} \mathrm{N} \quad \mathrm{NP}_{\mathrm{GEN}}$ ] have a uniform compositional interpretation?

\section{Uniform approaches and split approaches}

As we will illustrate in Section 4, given the possibilities that have been raised by work on typeshifting in the past decade or so, it seems that the semantics of any simple "NP's N" or "N NP $\mathrm{GEN}_{\text {" }}$ construction could be given either an analysis in which the genitive NP is an argument or one in which it is a modifier. In this paper we are not trying to settle all the relevant arguments for even one such construction. Rather, we wish to explore the available alternatives from a semantic point of view. A full analysis of any genitive construction in any language requires greater syntactic specificity than we are providing here, as well as a theory of the interaction among lexical, structural, and contextual factors. Moreover, relevant evidence may be of many kinds, including binding and extraction facts, behavior in coordinate constructions, iterability, word order constraints, and quantificational properties. There are, by now, many proposals for many such constructions in different languages in the literature, in a variety of theoretical frameworks, and we will not enter into the sometimes crucial syntactic debates that are involved in some of the competing analyses. However, with little more than the minimal syntactic assumptions noted above, we can address some of the central issues of semantics and compositionality.

To illustrate our concerns with a concrete example, let us discuss approaches to the semantics of the English genitive construction illustrated by the phrase book of John's. ${ }^{6}$

There are in principle three possibilities: a split approach and two kinds of uniform approach.

(i) One possibility is to split the construction into two different genitive constructions, treating “inherent $\boldsymbol{R}$ " genitives (brother of John's) as type-raised arguments and "free $\boldsymbol{R}$ " genitives (team of John's) as (intersective) modifiers (Partee 1983/1997; Barker 1995). This approach starts from the intuition that some genitives are arguments and some are modifiers, as will be illustrated in Section 4 below. If no uniform approach can be made to work (for a given genitive construction in a given language), a split approach may be necessary. One of our main points here will be, however, that raw intuitions of ambiguity or of argumenthood vs. modifierhood do not constitute real evidence. Most linguists would tend to prefer a uniform analysis if it can be made to work but, as Dowty (1997, 2000) argues, that is not an uncontroversial position. In the subsequent sections of this paper, we explore empirical arguments for and against the ambiguity of various genitive constructions.

(ii) One possibility of a uniform approach is to assimilate all cases to the "inherent $\boldsymbol{R}$ " reading, treating all genitives as arguments, or as type-lifted arguments. This option was introduced by Jensen and Vikner (1994), and further explored in Partee and Borschev (1998), Borschev and Partee (1999a, b), and Vikner and Jensen (2002). We describe this approach in Section 4 below, and show some empirical advantages of this approach over a split approach. In Section 5, we review arguments from Partee and Borschev (2001) to the effect that, in spite of these attractions, this uniform approach is not correct for all genitive constructions in all languages, although it may well be correct for some. These conclusions open up interesting typological questions and invite the task of finding more kinds of evidence for true arguments of nouns. 
(iii) Another possibility of a uniform approach is to assimilate all cases to the "free $\boldsymbol{R}$ " reading. A variant of that option was proposed by Hellan (1980). Partee (1983/1997) argued against it on the basis of the contrast among the (c) examples in (4-6), but we return to it in Section 6. On this kind of analysis, all genitives are modifiers. Within approaches to modifier genitives, recent work by Kolliakou (1999) shows the need for a further distinction between genitives as predicates of type $\langle$ e,t $\rangle$, i.e. as intersective modifiers, and genitives as non-intersective intensional modifiers of type $\langle\langle\mathrm{e}, \mathrm{t}\rangle,\langle\mathrm{e}, \mathrm{t}\rangle\rangle$. As we discuss in Section 6, challenges to treating all genitives as modifiers include the obligatoriness or near-obligatoriness of a genitive complement with some relational nouns and the apparent systematicity of argument-inheritance with some kinds of deverbal nouns. For the treatment of genitives as intersective modifiers, another problem is the apparent impossibility of some genitives in predicate position, as illustrated by the contrasts in (4-6) above. New evidence from ellipsis ambiguity militating against a modifier-only approach is also introduced in Section 6. We conclude that we cannot support a modifier-only approach but we believe that more work on such a possibility would be worthwhile.

\section{Two theories of genitives}

\subsection{The early Partee split approach}

Partee (1983/1997) proposed two distinct genitive constructions with relational and non-relational nouns, the latter incorporating a free relation variable $\boldsymbol{R}$ whose value must be supplied by context. On the other hand, (a modified version of) Jensen and Vikner (1994) offers a uniform interpretation of the genitive, with coerced type-shifting of the N-bar to a relational reading when necessary. The investigation of the differences between these two approaches, in part through an ongoing dialogue between Borschev and Partee and Jensen and Vikner over the past several years, has led us to an appreciation that the problem of the semantics of the genitive construction(s) is a much richer domain of inquiry than we had originally imagined, and to convergence on some issues and new questions on others.

A note concerning notation: in what follows we use CN for a ("plain") N-bar of type $\langle e, t>$ (oneplace predicate, with only a "referential" $\theta$-role (Williams 1981; the R role of Babby 1997), and TCN for a ("transitive" or "relational") N-bar of type $\langle\mathrm{e},\langle\mathrm{e}, \mathrm{t}\rangle\rangle$ like father, favorite movie. We sometimes use CNP and TCNP for phrasal constituents of those types.

The analysis of Partee (1983/1997) posits a split in the construction, with the N-bar supplying the relation if it is relational, and with the construction supplying a "free relation variable" if the Nbar is not relational. We illustrate the postnominal genitive, as in $(4 b),(5 b),(6 b)$, which Partee $(1983 / 1997)$ analyzed as more basic than the prenominal genitive, treating the prenominal genitive in (4a), (5a), (6a) as a composition of the postnominal genitive with an implicit definite determiner.

Postnominal genitive (of John's) combines with CN or TCN to make a CN. When a genitive NP combines with a plain $\mathrm{CN}$, type $\langle\mathrm{e}, \mathrm{t}\rangle$ : the construction provides a "free $\boldsymbol{R}$ ", a variable of type $<\mathrm{e},\langle\mathrm{e}, \mathrm{t}\rangle>$ which we write as $\boldsymbol{R}_{\boldsymbol{i}}{ }^{8}$

$$
\begin{array}{ll}
\text { of John's: } & \lambda \boldsymbol{P} \lambda \boldsymbol{x}\left[\boldsymbol{P}(\boldsymbol{x}) \& \boldsymbol{R}_{i}(\mathbf{J o h n})(\boldsymbol{x})\right] \\
\text { team of John's: } & \lambda \boldsymbol{x}\left[\operatorname{team}(\boldsymbol{x}) \& \boldsymbol{R}_{i}(\mathbf{J o h n})(\boldsymbol{x})\right]
\end{array}
$$

When a genitive NP combines with a TCN, type $\langle\mathrm{e},\langle\mathrm{e}, \mathrm{t}\rangle\rangle$, the TCN provides its "inherent $\boldsymbol{R}$ ". 
(10) of John's: $\quad \lambda \boldsymbol{R}[\lambda \boldsymbol{x}[\boldsymbol{R}(\mathbf{J o h n})(x)]]$ or equivalently, $\lambda \boldsymbol{R}[\boldsymbol{R}(\mathbf{J o h n})]$ teacher of John's: $\lambda x[$ teacher(John)(x)]]

Compositionally, these are derived as follows. For the modifier genitive that combines with a plain $\mathrm{CN}$, as in (9), the basic type of its genitive morpheme 's is $\langle\mathrm{e},\langle\mathrm{e}, \mathrm{t}\rangle\rangle$, as in (11a). It combines first with the e-type possessor ${ }^{9}$ John to form the one-place predicate genitive John's as in (11b); this is the form that occurs predicatively in (4a). We assume that of is a semantically empty element inserted for syntactic reasons in postnominal genitives, and that the postnominal modifier genitive of John's in (11c) is derived from the predicative form by a simple type-shift, analogous to the way a predicative adjective red of type <e,t> may be lifted to become an adnominal modifier red of type $\langle\langle\mathrm{e}, \mathrm{t}\rangle,\langle\mathrm{e}, \mathrm{t}\rangle\rangle$ ( team as shown in (9) above.

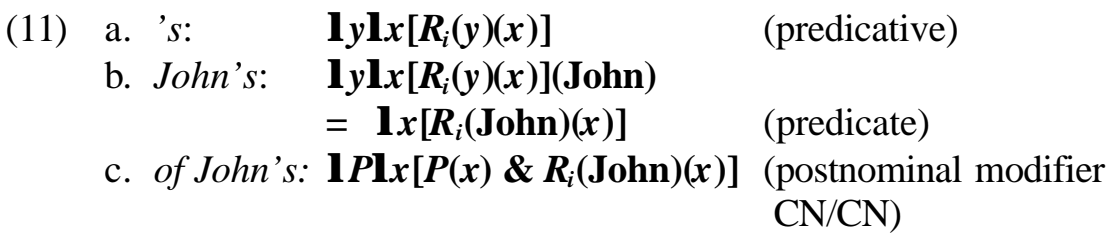

The "inherent $\boldsymbol{R}$ ", or argument genitive, is built from the homophonous genitive morpheme 's, shown in (12a) of type $\langle\mathrm{e},\langle\langle\mathrm{e},\langle\mathrm{e}, \mathrm{t}\rangle\rangle,\langle\mathrm{e}, \mathrm{t}\rangle\rangle\rangle$. It combines with the e-type possessor John to give a "detransitivizing modifier", a function from type $\langle e,\langle e, t\rangle\rangle$ to type $\langle e, t\rangle$, i.e. a type-lifted argument, as shown in (12b). When this argumental genitive combines with a relational noun like teacher, the result is as shown in (10), making John the first argument of the noun. (We again assume that of is semantically empty and is purely syntactic in motivation.)

$$
\begin{array}{ll}
\text { a. 's: } & \lambda y \lambda R[\lambda x[R(y)(x)]] \text { or equivalently } \lambda y \lambda R[R(y)] \\
\text { b. of John's: } & \lambda y \lambda R[\lambda x[R(y)(x)]](\text { John) } \\
& =\lambda R[\lambda x[R(\text { John })(x)]] \text { or } \lambda R[R(\text { John })]
\end{array}
$$

\subsection{The Jensen and Vikner uniform approach with coercion}

Jensen and Vikner (1994) propose that an analysis which incorporates coerced type-shifting in the sense of Partee (1987) should be able to do without two separate rules for the genitive. On their alternative analysis, which builds on the framework of Pustejovsky $(1993,1995)$, the genitive must always combine with a relational common noun (phrase), coercing a one-place predicate noun to a two-place relational meaning ("team" to an appropriate sense of "team-of"). Their analysis corresponds to the "inherent $\boldsymbol{R}$ " case of Partee (1983/1997) and, with a relational noun like teacher, the two analyses agree. The difference arises with a plain one-place $\mathrm{CN}$ like chair or team which, on their analysis, is coerced to a TCN interpretation. Jensen and Vikner follow Pustejovsky in appealing to the qualia structure of the lexical entry to guide the coercion, so that, for instance, the telic role of chair ("chairs are to sit in") licenses the shift of CN chair to TCN chair illustrated below. 


\section{(13) CN chair: $\quad \lambda x[\operatorname{chair}(x)]$ TCN chair: $\quad \lambda y \lambda x[\operatorname{chair}(x) \& \operatorname{sits}-i n(x)(y)]$}

Initially, we had some important disagreements with Jensen and Vikner concerning the degree to which lexical meaning drives coercion. In Vikner and Jensen (2002) and Partee and Borschev (1998), there is agreement that, on the most general version of their approach, the genitive construction should always demand a TCN to combine with, and if it finds instead a CN it will coerce it by whatever means are available and natural, sometimes lexical, sometimes pragmatic. (We make a less sharp distinction between lexically and contextually supplied shifted meanings than Jensen and Vikner do, because of the outlook on the integration of in formation from lexical and other sources described in Partee and Borschev (1998), Borschev and Partee (1998).) A "pragmatic" coercion is seen as shifting the noun to a relational reading that incorporates the free relation variable of Partee (1983/1997) into the shifted noun meaning. ${ }^{10}$

\section{(14) TCN team: $\quad \lambda y \lambda x\left[\operatorname{team}(x) \& R_{i}(x)(y)\right]$}

As in Partee's analysis, a felicitous use of an expression with a free variable requires that the context make salient a particular choice of value for the variable. Partee and Borschev (1998, 2000a) and Borschev and Partee (1999a) propose extensions to Jensen and Vikner's coercion approach to cover also the "contextual" cases. We also pointed to a need for more fine-grained coercion principles to cover phenomena involving the relational adjective favorite and the difference in preferred relation in the interpretation of John's movie and John's favorite movie ${ }^{11}$.

\subsection{Comparison of the two approaches}

One main difference between the two approaches concerns where a "free relation variable" is added in a case in which context is driving a pragmatic ally based coercion. Let us suppose that team of Mary's is such a case.

Jensen and Vikner (1994):

$$
\begin{array}{ll}
\text { of Mary's: } & \lambda \boldsymbol{R}[\lambda \boldsymbol{x}[\boldsymbol{R}(\operatorname{Mary})(\boldsymbol{x})]] \\
\text { (shifted) team: } & \lambda y\left[\lambda \boldsymbol{x}\left[\operatorname{team}(\boldsymbol{x}) \& \boldsymbol{R}_{i}(\boldsymbol{y})(\boldsymbol{x})\right]\right] \\
\text { team of Mary's: } & \left.\lambda \boldsymbol{x}\left[\operatorname{team}(\boldsymbol{x}) \& \boldsymbol{R}_{i}(\operatorname{Mary})(\boldsymbol{x})\right]\right]
\end{array}
$$

(16) Partee (1983/1997):

$$
\begin{array}{ll}
\text { of Mary's: } & \lambda \boldsymbol{P} \lambda \boldsymbol{x}\left[\boldsymbol{P}(\boldsymbol{x}) \& \boldsymbol{R}_{\boldsymbol{i}}(\operatorname{Mary})(\boldsymbol{x})\right] \\
\text { (non-shifted) team: } & \operatorname{team} \\
\text { team of Mary's: } & \left.\lambda \boldsymbol{x}\left[\operatorname{team}(\boldsymbol{x}) \& \boldsymbol{R}_{i}(\operatorname{Mary})(\boldsymbol{x})\right]\right]
\end{array}
$$

The final result is the same but for Jensen and Vikner the free relation variable comes in as part of the meaning of the shifted noun, while for Partee (1983/1997) it comes in as part of the meaning of the genitive construction itself. Does this difference in where the free relation variable is situated ever make a detectable difference? It does. 
Partee and Borschev (1998) give an empirical argument in favor of Jensen and Vikner's approach, based on an analysis of the example Mary's former mansion, suggested to us by Norvin Richards (p.c.). The argument rests on the four assumptions spelled out in (17).

(17) Assumptions:

(i) mansion is lexically a one-place noun.

(ii) former is an endocentric modifier, lexically a CN/CN, shiftable to a TCN/TCN. former as $\mathrm{CN} / \mathrm{CN}$ : former monastery, former dancer. former as TCN/TCN: former owner, former friend.

(iii) The "free relation" variable in this case has as one of its most salient values something like "owns" or "lives in".

(iv) Mary's former mansion has two readings:

Reading A: "a former mansion (perhaps now just a ruin) that is (now) Mary's".

Reading B: "something that was formerly Mary's mansion; it may still be a mansion, but it's no longer Mary's".

On the Partee (1983/1997) account, there is no motivation for any type-shifting to occur and the free relation "owns" will be introduced with the genitive Mary's, after former has combined with mansion. This means that the free relation ("owns") in the interpretation of the genitive Mary's will never be under the scope of former. As a result, Partee (1983/1997) can derive Reading A above, but not Reading B. The tree (18) shows the compositional structure of Mary's former mansion on the account of Partee (1983/1997).

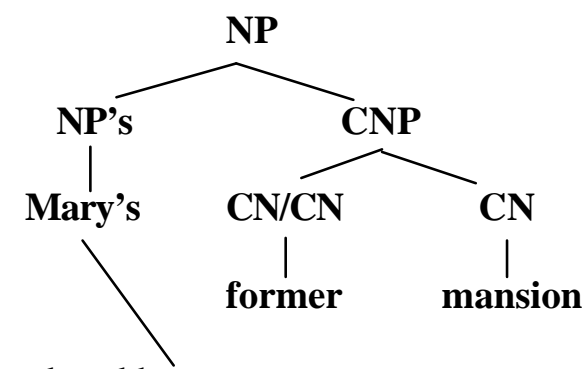

free $\boldsymbol{R}$ introduced here

Jensen and Vikner's account, with coercion of $\mathrm{CN}$ to TCN, does provide derivations for both readings, which Partee's account cannot. For Jensen and Vikner, Mary's coerces former mansion to a relational TCN. Given our assumptions, there are two ways that former mansion could shift to a TCN.

(i) Initially leave mansion as a $\mathrm{CN}$, treat former as $\mathrm{CN} / \mathrm{CN}$, combine them to form a $\mathrm{CNP}$, as on the Partee account; then shift that CNP to a TCNP, bringing in the free variable at that stage to get the shifted meaning of former mansion, shown below in (19):

$\lambda y\left[\lambda x[\right.$ former(mansion $\left.\left.)(x) \& R_{i}(y)(x)\right]\right]\left[R_{i}\right.$ : “is owned by"] 
This corresponds to Reading A above, with the free $\boldsymbol{R}$ introduced at the point where the CNP shifts to become a TCNP. The compositional structure would be almost identical to that in tree (18), differing only in where the free $\boldsymbol{R}$ is introduced.

(ii) Or shift mansion to a TCN, and former to a TCN/TCN, combine them to form a TCNP as shown below in (20):

$\lambda y[\lambda x[$ former(mansion-of $)(x)(y)]]$, where mansion-of is short for $\lambda y\left[\lambda x\left[\operatorname{mansion}(x) \& R_{i}(y)(x)\right]\right]$

This corresponds to Reading B above, with compositional structure as in (21) below.

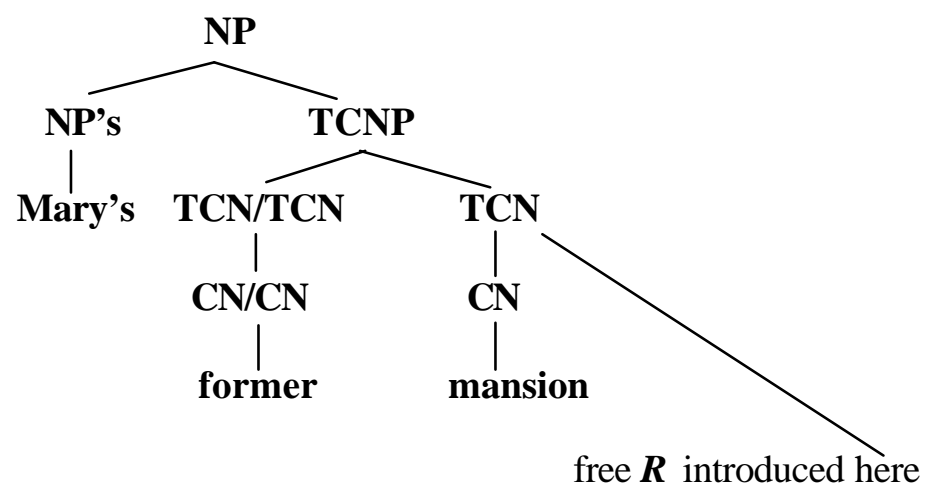

We assume that both of these ways of coercing the phrase former mansion are structurally available; different choices of lexical items or different contexts may favor one over the other, but since both are consistent with all the pinciples that we are aware of, the Jensen and Vikner approach successfully predicts the ambiguity and therefore has a clear empirical advantage over the Partee (1983/1997) approach. ${ }^{12}$

\section{Problems for the uniform "argument-only" approach}

In spite of the theoretical appeal of the uniform approach and its ability to solve the problem of Mary's former mansion, we are still not convinced that it is correct for English. Interestingly, the arguments against a uniform analysis for English genitives do not apply to Russian genitives. Russian seems to show a clearer split between a genitive construction which does indeed seem to be uniformly argumental ${ }^{13}$ and a prenominal possessive which is a modifier (but perhaps also ambiguous).

One of our main worries, discussed in Partee and Borschev (2001), concerns predicate genitives and our earlier observation that predicate genitives seem to favor "free $\boldsymbol{R}$ " interpretations, together with the fact that predicate genitives are not in a structural argument position unless one posits an empty head noun accompanying them.

As we examine predicate genitives and contrast them with the better candidates for argument genitives, it will emerge that the semantics of the clearest cases of predicate genitives seems to center on the notion of possession. Thus, the key distinction may not, after all, be "free $\boldsymbol{R}$ " vs. 
"inherent $\boldsymbol{R}$ " but, rather, a distinction between "possessive" modifiers and genitive arguments. We address this issue further in Sections 6 and 7.

\subsection{Predicate genitives: A problem for the uniform approach?}

If some genitives can occur as basic <e,t> predicates, that would suggest that when those same genitives occur inside the NP, they are basically modifiers, and not arguments, returning us to a version of the distinction posited in the earlier Partee (1983/1997) approach.

If there are no genitives that demand a treatment as basic type $<\mathrm{e}, \mathrm{t}>$ predicates, that would be an argument in favor of treating all genitives occurring inside an NP within the uniform approach of Jensen and Vikner.

If we find, on the contrary, that in some languages there are systematic differences in form and/or interpretation between certain genitives that occur only NP-internally and others that occur both predicatively and NP-internally, that would present a serious challenge to the uniform approach, at least for those languages. The issue is, however, empirically complex for at least two reasons:

(i) there may be independent reasons (syntactic or morphological) why some kinds of genitives (e.g. Russian genitives) cannot occur as predicates;

(ii) some predicate genitives may be elliptical full NPs; it is not always easy to tell.

Much of what follows is concerned with this problem. In the following sections, we look at evidence concerning predicate genitives in English, Russian, German, and Polish. The evidence supports the idea of two semantically different kinds of genitives, with some forms, such as English Saxon genitives, used for both.

One kind of genitives are argument genitives, which fit the Jensen and Vikner analysis. These occur in constructions with a relationally interpreted noun (or with an adjective like favorite plus a noun). Argument genitives do not occur in type $\langle\mathrm{e}, \mathrm{t}\rangle$ so, when they occur alone, they are interpreted as elliptical NPs with a relational noun implicitly understood. The Russian genitive appears to be of this type and we consider the Jensen and Vikner analysis correct for the Russian genitive construction.

The other kind of genitives are true predicative genitives, basically of type $\langle e, t\rangle$, interpreted approximately as in the corresponding analysis of Partee (1983/1997), but with the "free $\boldsymbol{R}$ " preferentially interpreted as some kind of "possession" or "control". To represent the way this distinction differs from the or iginal distinction of Partee (1983/1997), we will stop referring to the "free $\boldsymbol{R}$ " and refer instead to $\boldsymbol{R}_{\text {Poss. }}$. When this kind of genitive occurs inside an NP, it is a modifier rather than an argument. We believe that the Russian prenominal genitive forms discussed in Section 5.1.2. are of this type.

Since the English Saxon genitives, as well as possessive pronouns in all four of the languages looked at here, have both uses, we conclude that the uniform approach cannot be correct for those constructions.

But we are left with a puzzle concerning the large proportion of cases which could seemingly be analyzed either way: are they all "ambiguous"? We will return to this puzzle, which remains open, in Section 7. 


\subsubsection{Predicate genitives in English}

The nature of predicate genitives is less clear in English than in some other languages. It is difficult to be sure whether an apparent predicate genitive like John's in (4c), repeated below, is a simple one-place predicate with an $\boldsymbol{R}_{\text {Poss }}$ or "possession" reading, or is an argument genitive occurring as part of an elliptical NP, i.e. with John's implicitly in construction with another occurrence of team.

That team is John's.

But note the following, where the judgments marked concern the possibility of construing the predicate genitive as involving a relation corresponding to the noun in the subject NP.

(22) a. \#That father is John's.

b. \#That favorite movie is John's.

c. That teacher is John's.

d. His [pointing] father is also John's.

e. Dad's favorite movie is also mine.

f. ?That father is John's father.

The good examples in (22), namely (22c, d, e), all have predicate genitives that may be interpreted as elliptical NPs: ${ }^{14}$ John's teacher, John's father, my favorite movie. The bad examples (22a, b, f) all have intrinsically relational head nouns (or common noun phrase in the case of 22b) that have to be interpreted non-relationally in the subject but relationally in the predicate, assuming that $(22 \mathrm{a}, \mathrm{b})$ have elliptical predicate genitives. The head noun in the subject in examples $(22 a, b, f)$ must shift to a non-relational reading in order to be compatible with the demonstrative determiner that. ${ }^{15}$

It may be that there is a restriction (perhaps a processing restriction) on shifting an expression away from ts basic meaning and then back again. (The "bad" sentences are presumably not ungrammatical, but are nearly impossible with respect to the intended readings "John's father", etc.) In the good examples (22d, e) we have the rela tional readings of the head noun (phrases) in both the subject and the (elliptical) predicate. Example (22f), with two overt occurrences of the relational noun, the first shifted and the second not, is less bad than (22a), and is probably only awkward; it would presumably be acceptaable in the kind of context suggested by example (ii) in note 14.

The relevant difference between the good (22c) and the bad (22a) may be that teacher, unlike father, is lexically supplied with equally salient and closely related relational and non-relational readings, so that one would not have to suppress the relational reading by shifting in order to interpret teacher in the subject NP non-relationally.

The data above, reinforced by the Dutch data mentioned in note 13, strongly suggest that predicate genitives may sometimes be elliptical (Determiner-only) NPs. And if all bare genitives in all languages could be interpreted as elliptical NPs, then predicate genitives would not pose a problem for the uniform "argument-only" approach; the difference between possessive or genitive forms that can and that cannot occur "bare" as predicates would simply reflect constraints on NP ellipsis.

We believe, however, that not all predicate genitives are elliptical. We do not have conclusive arguments for English; there are several complicating factors, including problems in the analysis of 
copular sentences (Williams 1983; Partee 1986; Moro 1997; Heycock and Kroch 1998, 1999; Partee 1999a). So rather than try to support our intuitions about the English examples, we turn to some languages where we have found some syntactic and/or morphological distinctions that provide evidence for a distinction between modifier genitives and argument genitives. ${ }^{16}$

\subsubsection{Russian prenominal possessives vs. genitives}

In Russian, possessive pronouns and the normally prenominal quasi-adjectival possessive forms can occur in predicate position but genitive NPs cannot. ${ }^{17}$ This suggests that Russian genitive NPs are always arguments, and that the Jensen and Vikner uniform analysis with coercion of CNs to TCNs (extended to Russian in Borschev and Partee (1999a, b)) is correct for the Russian genitive construction. It also suggests that the Russian prenominal possessive forms, and possessive pronouns (see 5.1.4.), are at least sometimes modifiers.

The Russian prenominal possessive construction studied by Koptjevskaja-Tamm and Šmelev (1994) and by Babyonyshev (1997) is illustrated in (23) and the genitive construction in (24).
a. Petin
stul
Petja-POSS-M.SG. chair-M.SG.
'Petja's chair'
b. Mamin portret
Mama-POSS-M.SG. portrait-M.SG.
'Mama's portrait'
a. stul Peti
chair-M.SG. Petja-GEN.SG.
'Petja's chair'
b. portret mamy
portrait-M.SG. Mama-GEN.SG.
'Mama's portrait'

In these examples, both constructions can be used in describing the same range of cases; the possible relations of Petja to the chair or of Mama to the portrait are as various as with the English prenominal genitive. But the meanings do not "feel" identical. In the possessive construction in (23), we would like to claim (as did Schoorlemmer (1995)) that the possessive Petin, mamin acts as a modifier of the head noun. We believe that the prototypical interpretation of the possessive modifier is indeed possession. To maintain such a claim, "possession" must be understood in a broad sense to apply to a diverse range of relations; see Heine (1997). Thus in example (23b), possession may be possession proper, "authorship", or the relation of "being portrayed". But the possibility of expanding the sense of "possession" is evidently not unlimited. Thus "murderer of Petja" can be expressed in Russian by (25a) but not by (25b).
a. ubijca Peti
murderer-M.SG. Petja-GEN.SG.
'Petja's murderer' (murderer of Petja) 


\section{b. Petin ubijca \\ Petja-POsS-M.SG. murderer-M.SG. \\ \#'Petja's murderer' \\ [ok only as e.g. 'a murderer Petja has hired']}

In the genitive construction in (24a), we analyze Peti as an argument of the relation which connects it to stul. In the given case, the most salient relation could alternatively be seen as some kind of possession as well; but possession proper is not the prototypical interpretation for the genitive construction. The range of possible relations expressed with a genitive is extremely broad (cf. Knorina 1985, 1988, 1990, 1996; Borschev and Knorina 1990; Partee and Borschev 1998; Borschev and Partee 1999a, b).

While this set of data is not completely conclusive, it supports the hypothesis that the Russian genitive construction is correctly analyzed as uniformly argumental, i.e. that Jensen and Vikner's approach to English genitives is correct for Russian genitives. Further, we believe that the Russian prenominal "adjectival" possessives are basically modifiers, with the "free" $\boldsymbol{R}_{\boldsymbol{P} \text { oss }}$ as the core of their meanings (see the analysis in (33) below). However, the high overlap in possible interpretation of the two constructions, as illustrated in (23) and (24), is a puzzle.

\subsubsection{German possessive pronouns}

Tony Kroch (p.c.) suggested looking for languages that would give evidence from agreement behavior as to whether predicate genitives are more like simple (adjectival) predicates or more like full NPs. Sten Vikner (p.c) observed that German is a language that gives some evidence: Predicate adjectives in German do not agree with subjects, but predicate possessives do, suggesting that predicate possessives are indeed more like elliptical NPs than like simple $<e, t>$ predicates. ${ }^{18}$

(26) Diese Bücher sind alt/*alte.

These-N.PL books-N.PL are old/*old-PL

(27) Diese Bücher sind meine/*?mein.

These-N.PL books-N.PL are mine-PL/*mine

This would suggest that the uniform approach may be correct for German, if all apparent predicate possessives give morphological evidence of being elliptical NPs.

But it was further observed by Hans Kamp (p.c.) and others that actually, the non-agreeing form can sometimes be used. It is used only in "standard" German, not in colloquial German, and it has an "archaic" flavor. Most interestingly, it seems that there are semantic differences between the agreeing and the non-agreeing predicate possessive.

Further examples are given in (29) and (30). A newly naturalized citizen might say (29a), but (29b) suggests a conqueror is speaking. Any relation is possible in (30a), with the most likely possibility 
being the parent-child, but (30b) suggests a custody fight, i.e. a dispute about who is to be in "possession" of the children.

(29) a. Das Land ist (jetzt) meins.

The-N.SG land-N.SG is (now) mine-N.SG

b. Das Land ist jetzt mein.

The-N.SG land-N.SG is now mine (no agreement)

(30) a. Die Kinder sind meine.

The children are mine-PL

b. Die Kinder sind mein.

The children are mine. (no agreement)

In (28b), (29b) and (30b), the form which shows absence of agreement, in the way a predicate adjective would, is limited in its interpretation to "possession". In other words, the form in which the possessive pronoun appears to be a simple predicate of type $\langle e, t\rangle$ is interpreted in terms of a relation that appears to be associated with the genitive construction itself rather than with the semantics of any governing noun.

In contrast, the forms which appear to be elliptical NPs have a range of interpretations including possession but also including relations typical of argument genitives, where the relevant relation is determined principally by the noun to which the genitive supplies an argument. Typical choices for the genitive relation for the argument genitive interpretations in (28a), (29a) and (30a) are authorship, citizenship, and the parent-child relation, respectively.

Of course, "possession" itself can have metaphorical extensions, so the "possession" cases do not always have to be about ownership in a literal sense. But these distinctions nevertheless provide important evidence for the idea of two distinct genitives.

\subsubsection{Russian and Polish possessive pronouns}

In Russian, in the past tense, predicate nominals may be in the Instrumental case, particularly when indicating temporary relations. Babby (1973), Siegel (1976) and others have used case and other agreement phenomena to argue that some predicative adjectives are elliptical NPs and others are simple APs. The following data may provide a basis for distinguishing between predicate possessive pronouns that are, and those that are not, elliptical NPs.

(31) a. Èta strana byla kogda-to moej.

That-F.NOM.SG country-F.NOM.SG was-F.SG once my-F.INSTR.SG 'That country was once mine.' ("possession” or citizenship)

b. Èta strana byla kogda-tomoej stranoj.

That-F.NOM.SG country-F.NOM.SG was-F.SG once my -F.INSTR.SG country-F.INSTR.SG

'That country was once my country.' (“possession” or citizenship)

(32) a. Èta strana byla kogda-to moja.

That-F.NOM.SG country-F.NOM.SG was-F.SG once my-F.NOMSG

'That country was once mine.' ("possession" only) 


\section{b. * Eta strana byla kogda-to moja strana. \\ That-F.NOM.SG country-F.NOM.SG was-F.SG once my-F.NOM.SG country-F.NOM.SG 'That country was once my country.'}

A full predicate nominal is impossible in the nominative in the context of (32b), and in the same context, a nominative possessive pronoun can be interpreted only as a possessive, not as an argument genitive (even with a seemingly "free" relation). Thus the possessive in (32a) cannot reasonably be analyzed as an elliptical NP but must be a simple <e,t> predicate. Further, it is this occurrence of the predicate possessive that unambiguously denotes "possession". These data are similar to the German data, supporting the idea that there is a "possessive" predicate of type <e,t> instantiated at least by some possessive pronouns in German and Russian and possibly also by some predicative "NP's" forms in English, distinct from other cases of predicate possessives which are elliptical full NPs and in which the possessive may be an argument of an implicit relational noun.

Wayles Browne (p.c.) suggested that we should extend our data to include Polish because, in Polish, NP - BE - NP requires Instrumental on the predicate NP, whereas in Russian the predicate NP may or may not be Instrumental. Further, in Polish, NP - BE - Adj requires Nominative on the Adjective, whereas in Russian the predicate AP may be (i) short-form Adjective, (ii) long-form Nominative Adjective, or (iii) long-form Instrumental Adjective.

The corresponding Polish data are as follows. ${ }^{20}$
kraj
byl
kiedys' moim.
a. Ten
That-M.NOM.SG country-M.NOM.SG was-M.SG once my-M.INSTR.SG
'That country was once mine.' ("possession" or citizenship)
b. Ten kraj byl kiedys'
That-M.NOM.SG country-M.NOM.SG was-M.SG once
moim krajem.
my-M.INSTR.SG country-M.INSTR.SG
'That country was once mine.' ("possession” or citizenship; citizenship preferred)
a. Ten
kraj
byl
kiedys' mo'j.
That-M.NOM.SG country-M.NOM.SG was-M.SG once my-M.NOM.SG
'That country was once mine.' ("possession" only)
b. *Ten kraj byl kiedys'
That-M.NOM.SG country-M.NOM.SG was-M.SG once
mo'j kraj.
my-M.NOM.SG country-M.SG
'That country was once my country.' (ungrammatical)
c. Ten kraj to byl kiedys'
That-M.NOM.SG country-M.NOM.SG PRT was-M.SG once
mo'j kraj.
my-M.NOM.SG country-M.SG

'That country was once my country.' ("possession” or citizenship) 
The Polish data confirm the hypothesis that when a predicate possessive pronoun allows an argument reading, it is the remnant of an elliptical NP, and when it does not, it is not. The "possession" reading, which seems to be emerging as the clearest case of a non-argumental (or modifier) reading, can occur either in a remnant of an NP or as a bare <e,t $>$ predicate. This reinforces the idea that a genitive inside an NP can be either an argument or a modifier. However, a genitive which is an $\langle e, t\rangle$ predicate in a predicational construction cannot be an argument, presumably because it is not in construction with a head of which it could be the argument.

\subsubsection{Conclusions about predicate genitives}

We now believe that some predicate genitives really are plain $\langle\mathrm{e}, \mathrm{t}\rangle$ predicates, and that those have just a possession/control reading, which we take to be the semantics of the $\langle\mathrm{e}, \mathrm{t}\rangle$ genitive, as shown in (35) below. (Having reached this conclusion, we now prefer to refer to this type as "predicate possessives".) Other predicate genitives may be elliptical NPs whose interpretation may have the full range of possibilities that would be displayed by a full NP with a prenominal genitive occurring in such a position. (Note that a full NP may itself have meanings of types e, $\langle\mathrm{e}, \mathrm{t}\rangle$, or $\langle\langle\mathrm{e}, \mathrm{t}\rangle, \mathrm{t}\rangle$, depending on both its internal makeup and the position in which it occurs, so the study of the full range of meanings of bare genitives as elliptical NPs requires further research.)

$$
[J o h n ' s]_{\mathrm{PRED}}: \quad \lambda \boldsymbol{x}\left[\boldsymbol{R}_{\text {POSS }}(\mathrm{John})(\boldsymbol{x})\right] \quad \text { type : }\langle\mathrm{e}, \mathrm{t}>
$$

This conclusion supports the proposal that, in the case of argument genitives, the genitive relation comes principally from the relational noun, whereas in the case of the modifier genitive, whose prototypical interpretation is possession, the genitive relation comes from the genitive construction itself. The cases analyzed as "free $\boldsymbol{R}$ " in Partee 1983/1997 therefore should be split into two kinds. One kind should be assimilated to the $\boldsymbol{R}_{\text {PosS }}$ of the "possessive" genitive, and the other treated as in Vikner and Jensen (2002) and Borschev and Partee (1999a, b), as incorporated into a coerced relational reading of the head noun.

\subsection{Other problems for the uniform "argument-only" approach}

A second and related argument concerns acquisition. Children may acquire some kinds of genitives before they show clear mastery of relational nouns.

Mine! is one of the early expressions small children learn. At this stage, it seems to mean "control" or possession, compatible with an $\langle\mathrm{e}, \mathrm{t}\rangle$ reading, although we do not know how one could completely rule out the possibility that it is elliptical for something like My (mine) blanket! We believe that this usage pre-dates any evidence of children's understanding of relational nouns like daddy, brother as relational. We are not sure whether genitive NPs like Bobby's occur at this early stage. M. Tomasello (p.c.) suggests that it is only personal pronouns that are seen in early predicative uses.

If it is indeed the case that children acquire "possessive" genitives before they acquire relational nouns with relational type $\langle\mathrm{e},\langle\mathrm{e}, \mathrm{t}\rangle\rangle$, then the uniform argument approach would have to posit later reanalysis, while a split approach would say that that the earlier form persists and that the argument 
genitive is added hter. We assume that accretion is easier than reanalysis, so that would be an argument in support of the split approach.

Another problem for any uniform approach, either modifier-only or argument-only, comes from the complex patterns of constraints on multiple genitives found with many genitive constructions in various languages. While the data are complex and often controversial, at least some of the data suggest that the number of argument genitives that can occur with a given noun is rarely more than one (except in the case of deverbal nouns, which we are neglecting in this paper), and that when two or more genitives are able to occur with a noun, at least one of them must be a "possessive". This would be easiest to explain if the possessive is a modifier rather than another argument. The typical pattern of constraints suggests that a noun can have at most one genitive argument ${ }^{21}$ (although Babby (1997) and a few others have argued for two genitive argument positions in the Russian noun phrase). One would expect that a noun can have any number of modifiers but, if genitive modifiers are all of the same kind, "possessive", then a restriction to just one genitive modifier would be similar to the blocking of multiple adverbials sharing the same semantic function on a single verb.

\section{A possible uniform "modifier-only" approach}

In this section we describe a possible uniform "modifier-only" approach to the English genitive and other genitives which appear to have both modifier and argument uses. Such an approach could, in principle, preserve the insights of Jensen and Vikner's uniform "inherent-R" approach and might also help to provide a semantic perspective on the notion of "quasi-argumental modifier" that has been proposed by Grimshaw and others. This approach is similar in some important respects to that of Hellan (1980) and it appears to be subject to some of the same potential problems. Ultimately, we argue against it as a uniform treatment of English genitives, although we believe that some of the ideas sketched here have application to at least some parts of English and other languages and therefore deserve further research.

In Section 6.1., we show how such an approach might work, briefly and with some gaps. In Section 6.2., we discuss compositionality issues from the perspective of this kind of approach. In Section 6.3., we argue that even within a "modifier-only" approach, we will need to distinguish the simply predicative "possessives" from other "relational" genitives. At this point, it begins to look as though even if a uniform modifier approach can, in principle. be made to work, it may not be the right answer for languages like English. Indeed, in Section 6.4., we present a new argument we

have found, based on the distribution of readings in certain elliptical constructions, in favor of maintaining a distinction between argument genitives and $\langle\mathrm{e}, \mathrm{t}\rangle$ modifier genitives, at least for English.

\subsection{Steps toward a uniform modifier analysis}

Suppose we would like team of Mary's, teacher of Mary's, brother of Mary's, height of Mary('s), sky of Mary's all to look like instances of intersective modification by an <e,t $\rangle$ predicate. ${ }^{22}$ Then we might represent them as in (36). However, more must then be said about how the formulas in (36) are to be interpreted. 
(36) a. $\lambda \mathbf{x}\left[\operatorname{team}(\mathbf{x})\right.$ and $\left.\mathbf{R}_{\mathrm{GEN}}(\operatorname{Mary})(\mathbf{x})\right]$

b. $\lambda \mathbf{x}\left[\operatorname{teacher}_{\mathbf{1}}(\mathbf{x})\right.$ and $\left.\mathbf{R}_{\mathrm{GEN}}(\operatorname{Mary})(\mathbf{x})\right]$

c. $\lambda \mathbf{x}\left[\right.$ brother $_{1}(\mathbf{x})$ and $\left.\mathbf{R}_{\mathrm{GEN}}(\operatorname{Mary})(\mathbf{x})\right]$

d. $\lambda \mathbf{x}\left[\right.$ height $\mathbf{1}_{\mathbf{1}}(\mathbf{x})$ and $\left.\mathbf{R}_{\mathrm{GEN}}(\operatorname{Mary})(\mathbf{x})\right]$

e. $\lambda \mathbf{x}\left[\operatorname{sky}(\mathbf{x})\right.$ and $\left.\mathbf{R}_{\mathrm{GEN}}(\operatorname{Mary})(\mathbf{x})\right]$

Formula (36a), for instance, can be read informally as the property that something has if it is a team and it is Mary's, i.e. if it is a team and it stands in the relation $\mathbf{R}_{\mathbf{G E N}}$ with Mary. The meaning of (of) Mary's as a basic intersective modifier of type <e,t> that is used in these formulas is as shown in (37).

\section{$\lambda \mathbf{x}\left[\mathbf{R}_{\mathrm{GEN}}(\operatorname{Mary})(\mathbf{x})\right]$}

We also need axioms to tell us what sorts of relations can be "genitive relations". ${ }^{23}$ We sidestep this important issue here and simply make the assumption (38) that teacher $\mathbf{r}_{2}$ can be an appropriate value for $\mathbf{R}_{\mathbf{G E N}}$.

\section{teacher 2 can be $\mathbf{R}_{\mathrm{GEN}}$.}

Then we have to answer several questions. One concerns the interpretation of the one-place predicates in the representations above; another is the nature of $\mathbf{R}_{\mathbf{G E N}}$ (is it a variable or a constant?) and its place in the grammar. A third is the question of compositionality: how are such meanings derived from the meanings of the parts? Let us try to approach answers to these questions in several steps.

Step 1: Let us focus on the sortal part of the meaning of a relational noun. We can exploit the fact that every noun has a basic sortal part in its meaning. We can even define it, at least in some cases, as the projection onto the $x_{E}$-axis of the "whole" meaning of the noun, where the $x_{E}$-argument is the "external" argument, the "referential" argument. Note that this can be done whether or not the noun can ever be used as a plain sortal noun (as teacher, nose, portrait easily can be, and brother, favorite movie, edge normally cannot be), since even those for which an internal argument is obligatory still have this sortal part of their meaning. For "plain" (sortal) nouns, the sortal part of the meaning is the whole meaning.

We will refer to this definable kind of sortal meaning as the first projection of the relation denoted by the relational noun:

$$
\text { Sort }_{\text {brother }}=\lambda x . \exists y\left(\operatorname{brother}_{2}(y)(x)\right)=\text { first projection of } \text { brother }_{2}
$$

Two important parameters of semantic differences ${ }^{24}$ among relational nouns are the following: (a) whether the noun has a "normal" independent use as a plain sortal noun (of course in strong enough context, any noun can have a one-place use) and (b) if so, whether the sortal (one-place) variant of the noun has a meaning which amounts to more than just the first projection of the relational meaning (as teacher, lawyer does and brother does not).

Earlier examples suggested that if the meaning of a relational noun's one-place variant was nothing more than the first projection of its relational meaning, then that noun would not normally be usable as an independent one-place predicate. However, further examples make it clear that even 
mere first projections can be used independently if that property has cultural importance. In our society, being a mother or a parent is important, being a brother or an uncle normally is not. It is not only for nouns like teacher that sentences like (40a) are good; $(40 \mathrm{~b}, \mathrm{c})$ are also fine, but (40d, e) are not. ${ }^{25}$

(40) a. Many teachers voted for John.

b. Many mothers voted for John.

c. Many parents voted for John.

d. \# Many brothers voted for John.

e. \# Many uncles voted for John.

We suggest that the one-place predicates in (36) are related to the basic noun meanings in one of three ways: (i) The one-place predicate may itself be the basic noun meaning, as in (41a). (ii) It may be an independently established one-place alternate of a two-place relational noun, as in (41b). (iii) Otherwise (not counting the influence of strong contexts) by default it will be the first projection of the relational noun, as in (41c).

(41) a. $\lambda \mathbf{x}[\operatorname{team}(\mathbf{x})], \lambda \mathbf{x}[\mathbf{s k y}(\mathbf{x})]$ : the meanings of the plain CNs team, sky

b. $\lambda \mathbf{x}\left[\operatorname{teacher}_{\mathbf{1}}(\mathbf{x})\right]$ : generic agentive noun, "one who teaches"

c. $\lambda \mathbf{x}\left[\operatorname{brother}_{1}(\mathbf{x})\right], \lambda \mathbf{x}\left[\operatorname{height}_{1}(\mathbf{x})\right]$ : first projections of the TCNs brother $_{2}$, height

The one-place predicate teacher ${ }_{1}$ in its most basic use does not seem to be elliptical (as one-place friend $_{1}$ usually seems to be) and is not simply the first projection of the TCN teacher ${ }_{2}$, but rather the name of a profession, much like surgeon, actor.

Step 2: We should compositionally derive the sortal part of the meaning of a phrasal NP (CNP). In simple cases, it will just be the sortal part of the meaning of its head noun, but more work is needed to identify the principles which specify the effects of non-subsective adjectives and of adjectives like favorite. Modifiers may also further specify sortal information by way of their selectional restrictions and/or their content. As a first approximation, but not an adequate general account, it is probably reasonable to assume (42).

$$
\operatorname{Sort}_{C N P^{\prime}}=\lambda \boldsymbol{x} \cdot \exists \boldsymbol{y}\left(\mathbf{C N P}^{\prime}(\boldsymbol{y})(\boldsymbol{x})\right)=\text { first projection of } \mathbf{C N P}{ }^{\prime}
$$

Step 3: In order to unify the combination of a genitive phrase with $\mathrm{CN}$ and TCN, we need to assume a natural kind of "polymorphism", something we need for all sorts of noun-modifiers and verb-modifiers. We want to be able to say that adnominal (of) Mary's can take any kind of a CNP as argument, whether one-place or two-place or in principle n-place. The essence of the analysis will then be as in (43-44) (using $\mathrm{N}$ as a cover variable for any lexical or phrasal $\mathrm{CN}(\mathrm{P})$ or $\operatorname{TCN}(\mathrm{P}))$ :

(43) The genitive modifier (of) Mary's takes any N-type argument, keeps the sortal part of the N meaning and adds a free $\mathbf{R}_{\mathbf{G E N}}$ for the relation. 


\author{
of Mary's: \\ $\lambda N: N$ is a noun-meaning . $\lambda x .\left[(\operatorname{Sort}(N))(x) \& \mathrm{R}_{\mathrm{GEN}}(\operatorname{Mary})(x)\right]$
}

To further generalize this polymorphic operator to the 0-place case, we can follow the strategy of Montague (1970) and treat predicates as though they are modifiers of an empty noun entity. Since entity denotes a predicate true of everything in the domain, the predicative meaning given in (45) is reducible to that given in (46). This is one normal way for adjectives not originally of intersective type to shift to intersective modifiers.

$$
\begin{aligned}
& \lambda x .\left[\text { entity' }^{\prime}(x) \& \mathrm{R}_{\mathrm{GEN}}(\text { Mary) }(x)]\right. \\
& \lambda \boldsymbol{x} \cdot \mathbf{R}_{\mathrm{GEN}}(\operatorname{Mary})(\boldsymbol{x})
\end{aligned}
$$

For a plain $\mathrm{CN}(\mathrm{P})$, the sortal part of the meaning is simply the meaning; for a $\mathrm{TCN}(\mathrm{P})$, it is the sortal "part" of the meaning as discussed above.

Step 4: In the fourth step, in which we identify $\mathbf{R}_{\mathbf{G E N}}$, we are influenced by Optimality Theory and by the work of Dölling (1992, 1997), Bierwisch (1989), and Hobbs et al. (1993). What we need are principles that say that if the noun already had a relational part of its meaning, then that should normally be used, and the more obligatorily relational the noun is, the more strongly that inherent relation is preferred. There should be such a principle in some very general terms, something about "using all the meaning" or at least using all the relevant parts of the meaning.

There are also principles like those proposed by Frosch (1999) about $\mathbf{R}_{\mathbf{G E N}}$ being salient, being shared information, having suitable uniqueness properties. Further, there are principles relating to the content of the genitive relation, explored by Jensen and Vikner (1994, 1996), Vikner and Jensen (2002), and Partee and Borschev (2000a) - $\mathbf{R}_{\text {GEN }}$ likes to be agentive, it likes to be partwhole, it does not like to be telic ${ }^{26}$ in the sense of Pustejovsky 1995. Rakhilina (2001) argues that in Russian, a genitive relation should be a relatively "stable" relation, not an ephemeral one, and should not be the kind of relation normally expressed with dative or instrumental case (insofar as those can be semantically described.)

\title{
6.2. Compositionality issues
}

\subsubsection{The basic cases}

How do we put together the meaning of brother of Mary's and team of Mary's on this view? We are moving towards a view that blends unification with ordinary function-argument application: the genitive modifier acts as a polymorphic function that applies "alike" to both one-place CN's and two-place TCN's, yielding a one-place CNP which preserves the sortal part of the meaning of the noun and intersects it with the "genitive" predicate meaning shown in (46).

If the meanings of brother and of Mary's are as in (47a, b), function-argument application would give (47c). From there, (i) an axiom analogous to that in (38) would tell us that an available value for the variable $\mathbf{R}_{\mathbf{G E N}}$ is brother $_{2}$, and (ii) there should be a general principle to the effect that if the sortal part of brother is not a salient property on its own, any value for $\mathbf{R}_{\mathbf{G E N}}$ other than brother $_{2}$ will yield an anomalous (or at least very hard to interpret) reading. With the help of such principles we would arrive at (47d). 
(47)
a. brother:
$\lambda \mathbf{y} \lambda \mathbf{x}\left[\operatorname{brother}_{2}(\mathbf{y})(\mathbf{x})\right]$
b. of Mary's:
$\lambda N: N$ is a noun-meaning $\cdot \lambda x \cdot[(\operatorname{Sort}(N))(x)$
$\left.\& \mathbf{R}_{\mathbf{G E N}}(\operatorname{Mary})(x)\right]$

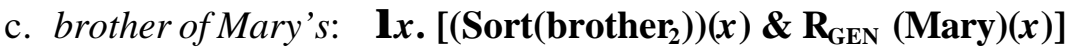

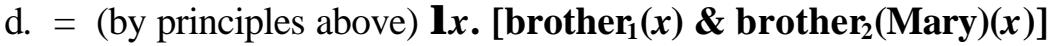

Analogously, if the meaning of team is as in (48a), function-argument application will give (48c). Since team is already a one-place predicate, its sortal part is simply team. And for the variable $\mathbf{R}_{\mathbf{G E N}}$ in this case, the context, including information in the lexical meaning of team, should provide a value, e.g. "plays for", "coaches", etc.
a. team:
$\lambda \mathbf{x}[\operatorname{team}(\mathbf{x})]$
b. of Mary's:
$\lambda N: N$ is a noun-meaning.$\lambda x \cdot[(\operatorname{Sort}(N))(x)$
$\left.\& \mathbf{R}_{\mathrm{GEN}}(\operatorname{Mary})(x)\right]$
c. team of Mary's: $\lambda \boldsymbol{x}$. [(⿻上丨t(team))(x) \& $\left.\mathbf{R}_{\mathrm{GEN}}(\operatorname{Mary})(\boldsymbol{x})\right]$
d. $=$ (by principles above) $\lambda x \cdot\left[\operatorname{team}(\boldsymbol{x}) \& \mathbf{R}_{\mathrm{GEN}}(\operatorname{Mary})(\boldsymbol{x})\right]$

Note the contrast between the English of $+\mathrm{NP}_{\mathrm{ACC}}$ construction (portrait of John), which is strictly argumental, and the postnominal genitive (portrait of John's), which allows any relational reading except that expressed by portrait of John. This contrast shows that there are evidently some "Blocking" principles: the reason that portrait of John's cannot usually mean what portrait of John must mean is presumably the very existence of portrait of John with its more specific meaning. There is no inherent prohibition of such a meaning, or even a dispreference for it, but it is blocked by the existence of the more specific alternative. One argument for this approach is that there is no such effect in prenominal position (John's portrait), where there is no alternative expression.

Such blocking principles need to be explored further as a potentially important part of the explanation of the typological differences across languages in the range of relations expressed by genitive constructions in "competition" with other constructions in the same language. For example, English genitives are not used for some of the relations expressed by genitives in Russian, apparently because of competition from the Noun-Noun compound construction in English (see the glosses of the examples in (7)).

\subsubsection{Mary's former mansion revisited}

Since much was made of the example Mary's former mansion in our earlier arguments in favor of Jensen and Vikner's uniform "argument-only" approach, we should examine how such an example might be handled, if it can be, on an alternative "modifier-only" approach.

As a first observation, we note that former affects the asserted part of the meaning of its modifiee and not the presupposed parts, a distinction we have not been explicitly representing. A former bachelor is normally interpreted as someone who is still adult, male, human but no longer unmarried. ${ }^{27}$

Suppose also that only lexical nouns can shift from CN to TCN (a welcome assumption, but one that was violated in the earlier account in Section 4). Then we could not assume that former and $\mathrm{CN}$ mansion could combine and then type-shift, as we did in (19) in Section 4.3. If former 
combines with CN mansion, and if we continue to assume that the most salient value of $\mathbf{R}_{\mathbf{G E N}}$ in this case is "possess", then we straightforwardly get Reading A: "a former mansion that is now Mary's".

In order to get Reading B:, "something that was formerly Mary's mansion", mansion would have to shift to a TCN or relational reading before it combines with former; but without Jensen and Vikner's uniform "argument-only" approach, we cannot appeal to coercion to account for such a shift.

Leaving open the question of what independent motivation, if any, can be found for such a shift, let us assume for the sake of pursuing this approach that such motivation can be found. Then relational mansion may be represented as follows:

$\lambda \mathbf{y} \lambda \mathbf{x}\left[\operatorname{mansion}_{\mathbf{l}}(\mathbf{x})\right.$ and $\left.\mathbf{R}_{\mathbf{G E N}}(\mathbf{y})(\mathbf{x})\right]$ where the most salient value of $\mathbf{R}_{\mathbf{G E N}}$ is "possess"

Applying former to this TCN mansion could then in principle target either part, depending on what was presupposed and what was focussed in the given context. Structurally, former could always apply just to the noun, ending up with either "formerly a mansion" (yielding a second derivation for "reading A") or "formerly owned by $y$ ", the reading shown in (50) below.

(50) former mansion [assuming $\mathbf{R}_{\mathbf{G E N}}$ is the focussed part of (49)] : $\lambda \mathbf{y} \lambda \mathbf{x}\left[\operatorname{mansion}_{\mathbf{1}}(\mathbf{x})\right.$ and PAST(possessed-by $(\mathbf{y})(\mathbf{x}))]$

However, there is still a problem in how the possessive Mary's combines with former mansion on this approach. Suppose we try to follow the model shown in (47), the derivation of brother of Mary's, with former mansion in place of brother.
a. former mansion: $\lambda \mathbf{y} \lambda \mathbf{x}\left[\operatorname{mansion}_{\mathbf{1}}(\mathbf{x})\right.$
and PAST(possessed-by $(\mathbf{y})(\mathbf{x}))]$
b. of Mary's: $\lambda N: N$ is a noun-meaning . $\lambda x$. $[(\operatorname{Sort}(N))(x)$
$\left.\& \mathbf{R}_{\mathrm{GEN}}(\operatorname{Mary})(x)\right]$
c. former mansion of Mary's: $\lambda \boldsymbol{x}$.[(Sort(51a))(x) \& $\left.\mathbf{R}_{\mathbf{G E N}}(\operatorname{Mary})(\boldsymbol{x})\right]$

What remains to be worked out for this approach is the further interpretation of (51c). It should be straightforward to derive mansion $_{1}$ as the sort in (51c); the greater challenge is to identify principles according to which the choice of $\mathbf{R}_{\mathbf{G E N}}$ in (51c) would be PAST(possessed-by(y)(x)). That is, to maintain the modifier approach, it is not enough to show that we can derive a reasonable relation-modifying interpretation for former in former mansion, but that when of Mary's combines with the result, the choice for $\mathbf{R}_{\text {GEN }}$ should be the unusual relation "formerly owned". This contrasts with the straightforward function-argument combination of TCNP former mansion with Mary's as a genitive argument as shown in tree (21) in Section 4.3. When the genitive can be interpreted as an argument, it is straightforward to get it under the scope of former, whereas if it is to be uniformly interpreted as an intersective modifier, it is not straightforward. ${ }^{28}$

At this point, while we have done our best to imagine how a modifier-only approach might work, we are not sanguine about the prospect of finding good independently motivated solutions to all of the problems we have noted along the way. In the next section we nevertheless proceed to the 
issue of predicate genitives from the perspective of this approach. But in Section 6.4. we present a new argument in favor of going back to a split approach (at least for English).

\subsection{Predicate genitives again}

Since the uniform meaning proposed above amounts to a type-raised "predicate-conjunction" meaning, it should be based on a simple predicative meaning (type <e,t>) as shown in (46), repeated below as (52); this is equivalent to the meaning derived by the strategy of Montague (1970) given in (45).

\section{Mary's $_{\mathrm{PRED}}: \lambda x . \mathbf{R}_{\mathrm{GEN}}($ Mary) $(x)$}

But at this point we should probably bear in mind the "Janus-faced" nature of the genitives that we noted in Section 5: for "pure" non-elliptical predicate genitives, it may not be right to call this a "genitive" relation at all; this is where the distinction between "genitive" and "possessive" may become important.

\section{Mary's $_{\text {PRED }}: \lambda x$. R Poss $_{(\text {Mary })(x)}$}

It is, in our minds, a question for further research how to argue for a distinction between two classes of potentially "free" relations; we suspect that the distinction will be one of prototypical preferences (cf. Dowty 1989) rather than an absolute one. Possibly, $\mathbf{R}_{\text {Poss }}$ should just be thought of as one of the most salient relations (or family of relations) accessible when there is no salient sortal information in the construction: not only in the predicative case, but in cases like anything of mine, all this stuff of John's, where the head noun has minimal lexical content.

To say all these things, we need $\mathbf{R}_{\mathbf{G E N}}$ as a notion; the grammar (and Universal Grammar) has to be able to talk about it, and it has to be able to describe constraints and preferences. So it is not just the bare logical notion of a two-place relation; it is a two-place relation "template" that is part of the interpretation of a particular construction.

The approach described here, while not fully worked out and still facing substantial problems, can be seen to differ in certain crucial ways from Partee (1983/1997) as well as from Jensen and Vikner (1994) and Vikner and Jensen (2002) (and from Borschev and Partee (1999a, b) insofar as we have been following Jensen and Vikner). We summarize the differences below:

(54) a. Partee 1983/1997: Two distinct constructions

(i) with inherent-R nouns, Mary's is $\lambda \mathbf{R} \lambda \mathbf{x}[\mathbf{R}(\operatorname{Mary})(\mathbf{x})]$ (a lifted argument).

(ii) with sortal nouns Mary's is $\lambda \mathbf{P} \lambda \mathbf{x}\left[\mathbf{P}(\mathbf{x}) \& \mathbf{R}_{\mathbf{G E N}}(\mathbf{M a r y})(\mathbf{x})\right]$ (a predicate lifted to become an intersective modifier).

b. Jensen and Vikner (1994): All as lifted arguments, forcing plain nouns and NPs to shift to relational meanings. The genitive "wants" a relational $\mathrm{TCN}(\mathrm{P})$ to combine with, "wants" to give it an argument.

c. This proposal: Related in part to Hellan (1980): Assimilate all to free-R case, by (a) splitting relational nouns into a "sortal part" plus a relation, (b) making Mary's a 
polymorphic function, and (c) having principles which help make sure that the "inherent R" of an inherently relational noun cannot easily be ignored.

On the current proposal, all genitives could be viewed as modifiers. There are remaining conceptual problems, particularly for the "inherent $\boldsymbol{R}$ " case. The goal would be to have enough general principles at work that one could simply say $\mathbf{R}_{\mathbf{G E N}}(\mathbf{M a r y})(\mathbf{x})$ and have all the rest follow.

Even if the conceptual problems can be solved, any uniform approach will have to wrestle with the problem noted earlier of the limitations on the occurrence of more than one genitive with a single noun, limitations which may be better described in terms of co-occurrences of distinct genitive structures.

\subsection{Another argument in favor of ambiguity}

We continue to wrestle with the issue of whether a uniform analysis is really correct for English genitives. After developing some steps towards a Hellan-style unification and becoming increasingly skeptical of such an approach, we have come up with a new argument in favor of keeping <e, $\mathrm{t}>$ possessives and argument genitives distinct.

The strategy behind the search for new evidence is as follows: we consider contexts that favor an elliptical NP analysis of bare genitives and compare the behavior of bare genitives in such contexts with their behavior in predicate position where we may or may not have an elliptical NP. If the behavior is systematically different, that could provide possible evidence that not all predicate bare genitives in English are elliptical NPs. The particular evidence we present here in fact provides evidence that the genitive relation is located differently in the two cases: as part of the meaning of possessive Mary's in the case of an <e,t> possessive (this is the kind of "free R" that we call $\mathbf{R}_{\mathbf{P o s s}}$ ), and as part of the noun (possibly after coercion) in the case of argument genitives (this is our " $\mathbf{R}_{\mathbf{G E N}}$ ", whether free ("pragmatic", "contextual") or inherent).

First we consider a sentence in which the NPs are in argument positions (not predicate position), so that we know that a bare genitive is a remnant of NP ellipsis.

\section{Sanderson's portraits are mostly better than his wife's.}

Here, the genitive relation can be any of owner, artist, subject (we limit our attention to those three possibilities, ignoring further possible contextual relations), but it must be same relation in Sanderson's portraits and his wife's [portraits]. That would follow if the $\mathbf{R}_{\mathbf{G E N}}$ relation is packed into the meaning of the noun portraits (in at least all cases except the $<e, t>$ possessive $\left.\mathbf{R}_{\mathbf{P o s s}}\right)^{29}$ and there is a deleted identical noun (whether or not it is a syntactic deletion; identity of semantic content is required in any case). That would NOT follow so clearly if $\mathbf{R}_{\text {GEN }}$ were always part of the meaning of the genitive, although it does not directly argue against that because there could be "parallel structure" effects.

Now we consider the hypothesis that when a bare genitive occurs in predicate position, it may or may not be a remnant of NP ellipsis (in English). Our new evidence for this hypothesis is based on examples like (56) below.

(56) If Kandinsky's portraits had all been Gabrielle Münter's, then I suppose they would all be in Munich now. ${ }^{30,31}$ 
We believe that the predicate genitive in (56) has exactly the following possible readings: ${ }^{32}$

(a) Independently of how we interpret Kandinsky's portraits, Münter's can express possession (ownership).

(b) If Kandinsky's is interpreted as one of the inherent relations (artist, subject), then Münter's can also express that same relation, but not a different inherent relation; i.e., if we interpret Kandinsky's portraits as portraits by Kandinsky, then Münter's can be interpreted as portraits by Münter but NOT as portraits of Münter. And conversely.

These judgements can be accounted for on the following assumptions:

(i) The predicative Gabrielle Münter's can be either a simple <e,t> predicate or an elliptical NP.

(ii) A simple <e,t> predicate possessive expresses "possession" (we assume that "agent", and "the one portrayed" are inherent relations, not cases of "possession").

(iii) A prenominal genitive can express either possession or any inherent relation.

(iv) Inherent relations reside in the noun, either lexically or via coercion.

So the choice in (i) leads to two possibilities: possession, or "same as the relation expressed in the antecedent genitive construction".

Note that the ambiguity of (56) helps to show that "parallel structure" alone does not force identity of interpretation of the genitive relation, which in turn gives greater significance to the non-ambiguity of (55).

This new evidence leads us to the conclusion that even if an argument-only or a modifier-only approach is in principle possible, the facts of English nevertheless force us to accept a split approach.

\section{Speculative hypotheses and remaining puzzles}

\subsection{Two competing prototypes?}

It has often been pointed out that an argument genitive is most like a direct object, an "internal argument", most intrinsic to relational nouns. A "possessor" genitive, on the other hand, is most subject-like, agent-like, less like an internal argument, more independent; perhaps with more work it can be shown to follow that it is hence more easily a predicate. In cases where we can distinguish all three possibilities of possessor, subject, and object (e.g. John's portrait), the possessor seems to be even more external than the subject, as evidenced by well-known hierarchies of interpretive possibilities of e.g. Russian Mamin portret Ivana 'Mama's portrait of Ivan('s)', where Mama must be higher than Ivan in the hierarchy Possessor > Agent > Theme.

We started from the idea that genitives with relational nouns are basic, and have been trying to figure out what adjustments take place when a genitive is used with a plain sortal noun.

Heine (1997) starts from the other end, so to speak, with have sentences as primary concern and predicate genitives as secondary, and adnominal genitives as a tertiary interest. Inherent relations have a subordinate place in the discussion; various notions of control and "possession" are at the forefront.

This makes us see genitives as Janus-faced. From our perspective, the deverbal nouns are in a sense archetypal relational nouns, with genitives most clearly arguments: John's arrival, the city's 
destruction. From Heine's perspective, the use of a have-like construction or of a genitive construction with deverbal nouns is more like the grammaticization of a metaphorical extension of possession and inalienables like Mary's hand are closer to the core. Perhaps the child's early That's mine! is even more core-like. For genitive constructions which include the kind of possessive predicative readings discussed in Section 5, it seems clear that they are not to be treated as uniformly arguments.

We have tried in the first parts of Section 6 to develop a version of the proposal of Hellan (1980) which could preserve many of the properties of Jensen and Vikner's uniform argument approach within a uniform modifier approach. But we argued that in the end it is preferable for genitive constructions like those in English to go back to a split approach, acknowledging that genitives may arise from either of two different prototypes, though with a wide overlap in the result.

\subsection{Hypotheses and puzzles}

We summarize below some of our specific hypotheses about particular genitive and genitive-like constructions in English and Russian.

1. The English of $+\mathrm{NP}_{\mathrm{ACC}}$ construction (portrait of John) is strictly argumental.

2. The English Saxon genitive (John's) can be used as a predicate, type <e,t>.

3. The English of $+\mathrm{NP}$ 's construction (portrait of John's) is ambiguously argumental/nonargumental.

4. The English prenominal NP's neutralizes the distinction between postnominal of $+\mathrm{NP}_{\mathrm{ACC}}$ and of + NP's. It can also be either argumental or non-argumental.

5. The Russian genitive (Maši), always postnominal, is always an argument. It can never be used as a predicate (caveats). (But it can be used with plain nouns to express all kinds of relations including possession, as predicted by Jensen and Vikner's coercion analysis.)

6. The Russian prenominal possessive (Mašin, -a) can be used as a predicate, it has certain limitations on its use as an argument, and it is either sometimes or never structurally an argument, although it can certainly fill argument roles.

The puzzle that emerges is that there seem to be argumental genitive constructions and modifier possessive constructions that have a very great overlap in what they can express. If this is correct, it means that we cannot use "intuitions" of argumenthood as a good guide to whether something is "really" an argument at a given level of structure. As Dowty (1997, 2000) has argued, the distinction between modifiers and arguments need not be inherently sharp. Fleshing out more specific proposals about the relevant structures is necessarily a theory-dependent matter and we do not intend to undertake it without the collaboration of syntacticians. There are many different proposals in the literature for different argument and non-argument positions/sources for genitives and possessives in English, Russian, and other languages.

The bottom line seems to be that type-shifting and lexical meaning shifts make many compositional routes available to very similar net outcomes. The line between arguments and modifiers is not intrinsically sharp in terms of what is being expressed, and can only be investigated in theory-dependent ways. It is hard to find sharp differences between a theory in 
which the genitive construction itself contributes a "possessive" relation and a theory in which the genitive construction causes the head $\mathrm{N}$ or $\mathrm{N}$-bar to shift to a relational interpretation possibly involving a "possessive" relation as one of its "preferred" relations. At this point we believe that both kinds of analyses have their place; the arguments we have found for a split approach for English and for the languages discussed in Section 5 are arguments that indeed genitives are sometimes modifiers and sometimes arguments. Genitives are evidently a domain of great semantic flexibility, where we have to find detailed language-particular evidence to try to sort out how lexical semantics, compositional semantics, and type-shifting possibilities interact in each particular construction.

\section{Notes}

1. The authors wish to thank many colleagues for suggestions and discussion, especially Carl Vikner, Per Anker Jensen, Elena Paducheva, Ekaterina Rakhilina, and two anonymous referees. In addition to the conference in Oslo for which this paper was prepared, parts of this material were presented by one or both authors in graduate courses in Leipzig, Potsdam, Kolding, Moscow, Prague, and São Paulo, in a reading group at UMass Amherst, and in lectures in Berlin, Munich, Kleinwalsertal, Austria, at ESCOL 1999, in Bloomington, Swarthmore, Tel Aviv, Stanford, and at Sinn und Bedeutung 2000 in Amsterdam. We are grateful to members of those audiences for useful suggestions. The first parts of this paper overlap substantially with the first parts of Partee and Borschev (2001), and the whole paper is a revised version of Partee and Borschev (2000b).

This material is based upon work supported by the National Science Foundation under Grant No. BCS-9905748.

2. As noted in the next section, there is no perfect term to cover the whole range of "genitive" and "possessive" constructions. We use "genitive" as our neutral cover term, reserving "possessive" for notional possessives. The first two examples in (1b) are not morphological genitives; see (1d-e) in the next section.

3. For Russian, this applied to the postnominal genitives illustrated below in (1d) but not to the prenominal possessives of (1e).

4. We use English and Russian for illustrative purposes, abbreviated below as E and R.

5. We are grateful to Marcel den Dikken (p.c.) for suggesting that one should explore a possible approach on which the genitive in (1) is a complement of the lexical adjective favorite, so that genitives, when complements, would always be complements of some lexical item. That could certainly be made to work semantically, as long as the adjective favorite is always a function applying to the noun's meaning. As den Dikken notes, "it does complicate the syntax at first blush"; we suspect that a fuller investigation might best be carried out in connection with a study of the interaction of genitives with superlative and superlative-like constructions as in John's best picture, John's first picture.

6. There is already a problem in using this construction for illustration, since a number of authors, including Barker (1995), have argued that the English postposed genitive is a reduced partitive, book of John's books, and that there is therefore no simple construction of the form $\left[\mathrm{N} \mathrm{N} \mathrm{NP}_{\mathrm{GEN}}\right]$ in English. The reason we are not using the construction John's book for our basic case is that the prenominal genitive in English seems to combine the "basic" genitive with an implicit definite article. We are assuming here that the postposed genitive is a basic construction in English (see also Lyons 1986), but the general points we make would also hold for the prenominal genitive "minus the meaning of the definite article". Thanks to Michael Brody (p.c.) for noting that one should of course explore the "underlying position" of the prenominal genitive, which may move into a determiner position from somewhere else, at least in theories with syntactic movement.

7. This point is made more systematically for a wide range of constructions in Dowty (2000). 
8. As with the use of free variables like $\boldsymbol{x}_{\boldsymbol{i}}$ to represent pronouns used without linguistic antecedent, we assume as a felicity condition on the use of free $\boldsymbol{R}_{\boldsymbol{i}}$ that the context should make it sufficiently clear to the hearer what particular relation the speaker has in mind.

9. We do not discuss quantifier possessors in this paper. As a first approximation, we would follow the analysis of Bach and Partee (1980) which gives quantifier possessors like every student's widest scope within the noun phrase but does not allow a quantifier possessor to have scope independently of its noun phrase. See also Vikner and Jensen (2002).

10. But see Storto (2000) for observations about the distribution of contextually supplied relations that challenge some of the assumptions made in our work. We do not address those challenges here.

${ }^{11}$ Vikner and Jensen (2002) address the issue of favorite in a manner consistent with the points raised here.

12. An alternative analysis of the ambiguity, based on different assumptions which we do not share, has since been offered by Larson and Cho (1999). As noted by Marcel Den Dikken (p.c.), one non-standard assumption we are making is that phrasal categories (like TCNP) can take arguments; this is a standard assumption in Categorial Grammar (see e.g. Bach 1980) but not in most other frameworks.

13. Our claim that the Russian genitive uniformly has argument status has been chalenged by some colleagues; we acknowledge the existence of some problematic data but need to study it further.

14. We thank Ash Asudeh (p.c.) for example (1c), and Ekaterina Rakhilina and Elena Paducheva for examples (1d, e). We are also grateful to Per Anker Jensen for similar examples, and to all of them for helpful discussion of the possible differences between the good and bad examples. We thank M. den Dikken for pointing out that in Dutch, the predicate possessive in example (1c) is even more clearly an elliptical NP than in English and that Dutch, furthermore, is a language which clearly distinguishes elliptical from non-elliptical predicate possessives. In the Dutch rendition of (lc), the d-word die, signalling the presence of nominal structure, is obligatory, as shown in (i).

(i) Die docent is *(die) van Jan.

That teacher is *(that) of Jan

'That teacher is Jan's.'

By contrast, in (ii) both options are possible.

(ii) Die auto is (die) van Jan.

That car is (that) of Jan

'That car is Jan's.'

15. An anonymous referee suggests that $(1 \mathrm{a}, \mathrm{b}, \mathrm{f})$ are bad simply because father and favorite movie cannot be used non-relationally, as would be required for occurrence in the subject position of these sentences. We only partly agree. We believe that they can be used non-relationally, with a corresponding meaningshift, as in (i-iii) below but that, once they have been shifted to a non-relational meaning, they cannot support ellipsis with their original relational reading, which is what would be required for $(1 \mathrm{a}, \mathrm{b}, \mathrm{f})$ to be good.

(i) Some fathers are stricter than others.

(ii) That father over there in the playground isn't having much fun.

(iii) Very few favorite movies come out of Hollywood anymore.

(= "very few of anyone's favorites")

In a context in which (ii) above would be used, some speakers may be able to accept (la), but we believe that even in such a context, John's in (1a) could not be understood as John's father. Apparent intuitions to the contrary may involve a genitive relation corresponding to something like "assigned to", "associated with", "paired with", which might in the given context be extensionally equivalent to the "father of" relation. This issue, which often arises in discussions of the data, deserves further investigation.

16. The material in this section of the paper is drawn in large part from Partee and Borschev (2001).

17. Caveats must be put on the statement that genitive NPs cannot occur in predicate position in Russian; but the conditions under which they can occur are relatively special.

18. Further evidence that these predicate possessives are elliptical NPs was provided by Sigrid Beck and Irene Heim (p.c.): the possessive pronoun in (1) can be followed by adjectives (i.e. there can be ellipsis 
of just the head noun), while the adjective in (1) and the adjective-like possessive pronoun in (lb) cannot be. Thanks to Claudia Maienborn for correcting the mistakes in our earlier rendition of these examples.

(i) Diese Bücher sind meine alten.

These-NPL. book-N.PL are my-N.PL. old-N.PL.

'These books are my old ones.'

(ii) *Diese Bücher sind teuer neu(en).

ThesenPL. book-N.PL. are expensive new

'These books are expensive new ones.'

19. One anonymous referee considers "any relation" too strong a statement. We have encountered considerable speaker variation on these examples, but the intuitions we report seem to be in the majority.

20. Thanks to Ania Lubowicz and Anita Nowak for judgments. For (1a), Anita reports no preference for one reading or the other, while for (1b) she reports a preference for the "citizenship" reading. Both rejected (1b) as ungrammatical; Ania suggested that it should be corrected to (1c), which she finds possibly ambiguous. Both agreed that (la) is unambiguously "possession" only, where as (la) allows either reading. The basic judgments given above in the text for $(1 \mathrm{a}, \mathrm{b})$ and $(1 \mathrm{a}, \mathrm{b})$ were further confirmed by Janusz Bien, Bozena Cetnarowska (and by a substantial majority of a group of 12 students of hers), Bozena Rozwadowska, Piotr Banski, and Joanna Blaszczak, to all of whom we are grateful.

21. We are grateful to an anonymous referee for reminding us that this statement is not fully general and that it makes a difference how many different kinds of genitives a language has. As the referee notes, in German it is fine for a deverbal noun to have both a prenominal (Saxonian) possessive/"subjective" and a postnominal "objective" genitive as well.

22. We use subscripts 1 and 2 to represent the one-place predicate and two-place relation versions of nouns. Thus, teacher ${ }_{1}$ is of type $\langle e, t\rangle$, while teacher $\mathbf{~}_{2}$ is of type $\langle e,\langle e, t\rangle\rangle$. We discuss the meanings of oneplace versions of normally two-place nouns below.

23. We are grateful to Ekaterina Rakhilina (p.c. and lecture in Apresjan's seminar in 2001) for pointing out the need to uncover the principles that regulate the choice of e.g. genitive vs. dative for "argumental modifiers" in Russian. Principles are also needed concerning the choice of e.g. genitive modifier vs. noun-noun compound in English.

24. Thanks to Ash Asudeh (p.c.), who first brought the importance of these issues to our attention with examples using the noun teacher.

25. We mark the "bad" examples here with the symbol "\#”, indicating that they are normally anomalous, but not ungrammatical. As usual, a sufficiently strong context can render them fully felicitous.

26. This provides an additional argument for treating the "kind-modifying" possessives studied by Munn (1995) and Strauss (ms. 2002) as a distinct construction, since "telic" readings are the first choice for such possessives. Compare the two readings of children's poems: if we mean poems of some particular children, the agentive reading is most salient, but as a kind of poems, a "for" reading is most salient.

27. The analogous observation in the case of sentential negation is a standard test for presupposition vs. assertion.

28. There is, however, a possibility that former could apply to mansion of Mary's and that this order of semantic combination might even be possible in the case of the prenominal genitive in Mary's former mansion if the visible surface structure is not isomorphic with the semantic structure. More work needs to be done on this issue.

29. We assume that an $\langle\mathrm{e}, \mathrm{t}\rangle$ possessive can act as an ordinary intersective modifier in an NP; in that case the N may remain one-place and not shift to a "transitive" reading. So, if Sanderson's is an <e,t> possessive, deletion of an identical one-place noun portraits will mean that his wife's can also only be an $\langle\mathrm{e}, \mathrm{t}\rangle$ possessive. In all the other cases, the meaning of some particular relation will be packed into the noun portraits. 
30. Kandinsky and Münter were both artists, both did some portraits of each other and featured in portraits by other people as well, and he left a lot of paintings with her when he left Munich, and she eventually gave those paintings to the city of Munich. So we hope that all sorts of counterfactuals involving who painted what and of whom, and who was in possession of whose paintings, might all be pragmatically reasonable. (Some of the paintings were sufficiently abstract that one could also imagine there being uncertainty as to who was the one portrayed, if anyone. We do not think there is actually any confusion about that, but it is not unimaginable.)

31. It is not easy to find plausible examples in which we can have potential ambiguity among possession and some inherent- $\mathrm{R}$ reading while having one of the possessives in a predicate position. We have purposely put them in the antecedent of a counterfactual to try to help make plausible a reading where we can imagine portraits having a different artist or a different subject in addition to the possibility of different owner. The latter is normally by far the easiest to imagine being different, which can obscure judgments about other possibilities.

32. Thanks to the English-speaking participants in our March 2002 Mathesius Institute lectures for judgments. 


\section{References}

Babby, Leonard H.

1973 The deep structure of adjectives and participles in Russian. Language 49: 349-360.

1997 Nominalization in Russian. In Formal Approaches to Slavic Linguistics, The Cornell Meeting 1995, W. Browne, E. Dornisch, N. Kondrashova, and D. Zec (eds.), 54-83. Ann Arbor: Michigan Slavic Publica tions.

Babyonyshev, Maria

1997 The possessive construction in Russian: A crosslinguistic perspective. Journal of Slavic Linguistcs 5(2): 193-230.

Bach, Emmon

1967 Have and be in English syntax. Language 43(2): 462-485.

1980 In defense of passive. Linguistics and Philosophy 3: 297-341.

Bach, Emmon, and Barbara H. Partee

1980 Anaphora and semantic structure. In Papers from the Parasession on Pronouns and Anaphora, Jody Kreiman and Almerindo E. Ojeda (eds.), 1-28. Chicago: Chicago Linguistic Society.

Baker, C. L.

1978 Introduction to Generative Transformational Syntax. Englewood Cliffs, NJ: Prentice-Hall.

Barker, Chris

1995 Possessive Descriptions. Stanford: CSLI Publications.

Bierwisch, Manfred

1989 Event nominalizations: Proposals and problems. In Wortstruktur und Satzstruktur, W. Motsch (ed.), 1-73. Berlin: Akademie Verlag.

Borschev, V. B., and L. V. Knorina

1990 Tipy realij i ix jazykovoe vosprijatie [Types of entities and their perception in language] In Language of Logic and Logic of Language, 106-134. Moscow.

Borschev, V. B., and Barbara H. Partee

1998 Formal and lexical semantics and the genitive in negated existential sentences in Russian. In Formal Approaches to Slavic Linguistics 6: The Connecticut Meeting 1997, Željko Boškovic, Steven Franks, and William Snyder (eds.), 75-96. Ann Arbor: Michigan Slavic Publications.

1999a Semantika genitivnoj konstrukcii: raznye podxody $\mathrm{k}$ formalizacii [Semantics of genitive construction: different approaches to formalization]. In Typology and Linguistic Theory: From Description to Explanation. For the 60th birthday of Aleksandr E. Kibrik, Ekaterina V. Rakhilina, and Yakov G. Testelets (eds.), 159-172. Moscow: Jazyki Russkoj Kul'tury.

1999b Semantic types and the Russian genitive modifier construction. In Formal Approaches to Slavic Linguistics: The Seattle Meeting 1998, K. Dziwirek et al. (eds.), Ann Arbor: Michigan Slavic Publications.

Dölling, Johannes

1992 Flexible Interpretation durch Sortenverschiebung. In Fügungspotenzen, I. Zimmermann and A. Strigin (eds.), 23-62. Berlin: Akademie Verlag.

1997 Semantic form and abductive fixation of parameters. In From Underspecification to Interpretation. Working Papers of the Institute for Logic and Linguistics, R. van der Sandt, R. Blutner, and M. Bierwisch (eds.), 113-138. Heidelberg: IBM Deutschland.

Dowty, David

1989 On the semantic content of the notion "thematic role". In Properties, Types and Meanings. Vol. II. G. Chierchia, B. Partee, and R. Turner (eds.), 69-130. Dordrecht: Kluwer.

1997 Adjunct-to-argument reanalysis in a dynamic theory of grammar: The problem of prepositions. Paper presented at the Blaubeuren Semantics CCG/adj-arg Conference, University of Tübingen, March 1997.

2002 The dual analysis of adjuncts/complements in Categorial Grammar. In this volume. 
Freeze, Ray

1992 Existentials and other locatives. Language 68: 553-595.

Frosch, Helmut

1999 German "attributive" genitives as adjuncts. Paper presented at the Conference "Approaching the Grammar of Adjuncts”, 22-25 Sep 1999, Oslo.

Grimshaw, Jane

1990 Argument Structure. Cambridge: MIT Press.

Heine, Bernd

1997 Possession: Cognitive Sources, Forces, and Grammaticization. Cambridge: Cambridge University Press.

Hellan, Lars

1980 Toward an integrated theory of noun phrases. Dissertation, Trondheim University.

Heycock, Caroline, and Anthony Kroch

1998 Inversion and equation in copular sentences. In ZAS Papers in Linguistics 10, A. Alexiadou, N. Fuhrhop, U. Kleinhenz, and P. Law (eds.), 71-87. Berlin: Zentrum für Allgemeine Sprachwissenschaft.

1999 Pseudocleft connectivity: Implications for the LF interface level. Linguistic Inquiry 30: 327364.

Hobbs, J. R., M. E. Stickel, D. E. Appelt, and P. Martin

1993 Interpretation as abduction. Artificial Intelligence 63: 69-142.

Jensen, Per Anker, and Carl Vikner

1994 Lexical knowledge and the semantic analy sis of Danish genitive constructions. In Topics in Knowledge-based NLP Systems, S. L. Hansen and H. Wegener (eds.), 37-55. Copenhagen: Samfundslitteratur.

1996 The double nature of the verb have. In LAMBDA 21, OMNIS Workshop 23-24 Nov. 1995, 25-37. Handelshøjskolen i København: Institut for Datalingvistik.

Knorina, L. V.

1985 Ob interpretacii genitivnyx konstrukcij [On the interpretation of genitive constructions]. Theses of the workshop "Semiotic foundations of intellectual activity". Moscow: VINITI.

1988. Klassifikacija leksiki i slovarnye definicii [Lexical classification and dictionary definitions]. In Nacional'naja specifika jazyka i ee otraženie v normativnom slovare, ed. Ju.N. Karaulov, 60-63. Moscow: Nauka.

1990 Narušenija socetajemosti i ra znovidnosti tropov v genitivnoj konstrukcii [Violations of cooccurence and varieties of tropes in genitive construction]. In Contradictions and Anomalies of Text, 115-124. Moscow.

1996 The range of biblical metaphors in smikhut. Moscow Linguistic Journal 3: 80-94.

Kolliakou, Dimitra

1999 De-Phrase extractability and Individual/Property denotation. Natural Language and Linguistic Theory 17(4): 713-781.

Koptjevskaja -Tamm, Maria, and Aleksej Šmelev

1994 Alešina s Mašej stat'ja (o nekotoryx svojstvax russkix “pritja žatel'nyx prilagatel'nyx”) [Aleša and Maša's article (on some properties of Russian "possessive adjectives)]. ScandoSlavica 40: 209-228.

Landman, Fred, and Barbara H. Partee

1984 Weak NPs in HAVE sentences. Draft abstract. University of Massachusetts, Amherst.

Larson, Richard, and Sungeon Cho

1999 Temporal adjectives and the structure of possessive DPs. In Proceedings of WCCFL 18, S. Bird, A. Carnie, J. D. Haugen, and P. Norquest (eds.), 299-311. Cambridge: Cascadilla Press.

Lyons, Christopher

1986 The syntax of English genitive constructions. Journal of Linguistics 22: 123-143. 
Montague, R.

1970 English as a formal language. In Linguaggi nella Società e nella Tecnica, B. Visentini et al. (eds.), 189-224. Milan: Edizioni di Comunità. Reprinted in Montague (1974), 188-221.

1973 The proper treatment of quantification in Ordinary English. In Approaches to Natural Language, K. J. J. Hintikka, J. M. E. Moravcsik, and P. Suppes (eds.), 221-242. Dordrecht: Reidel. Reprinted in Montague (1974), 247-270.

1974 Formal Philosophy: Selected Papers of Richard Montague, edited by Richmond Thomason. New Haven: Yale University Press.

Moro, Andrea

1997 The Raising of Predicates. New York: Cambridge University Press.

Munn, Alan

1995 The possessor that stayed close to home. In Proceedings of the Western Conference on Linguistics (WECOL 24), V. Samiian and J. Schaeffer (eds.), 181-195.

Partee, Barbara H.

1987 Noun phrase interpretation and type-shifting principles. In Studies in Discourse Representation Theory and the Theory of Generalized Quantifiers (GRASS 8), J. Groenendijk, D. de Jongh, and M. Stokhof (eds.), 115-143. Dordrecht: Foris.

1983/1997 Uniformity vs. versatility: The genitive, a case study. Appendix to Theo Janssen (1997), Compositionality, In The Handbook of Logic and Language, Johan van Benthem and Alice ter Meulen (eds.), 464-470. New York: Elsevier.

1995 Lexical semantics and compositionality. In An Invitation to Cognitive Science, 2d ed. Vol. 1: Language, Lila Gleitman and Mark Liberman, (eds.), 311-360. Cambridge: MIT Press.

1999a Copula inversion puzzles in English and Russian. In Formal Approaches to Slavic Linguistics: The Seattle Meeting 1998, K. Dziwirek et al. (eds.), Ann Arbor: Michigan Slavic Publications. Also in UMOP 23: Issues in Semantics and its Interface, Kiyomi Kusumoto and Elisabeth Villalta (eds.), 183-208. Amherst: GLSA Publications 2000.

1999b Weak NP's in HAVE sentences. In JFAK: A Liber Amicorum for Johan van Benthem on the occasion of his 50th Birthday, CD-Rom, Jelle Gerbrandy, Maarten Marx, Maarten de Rijke, and Yde Venema (eds.), Amsterdam: University of Amsterdam. Accessible at: http://www.illc.uva.nl/j50/.

Partee, Barbara H., and Vladimir Borschev

1998 Integrating lexical and formal semantics: Genitives, relational nouns, and type-shifting. In Proceedings of the Second Tbilisi Symposium on Language, Logic, and Computation, R. Cooper and Th. Gamkrelidze (eds.), 229-241. Tbilisi: Center on Language, Logic, Speech, Tbilisi State University.

2000a Possessives, favorite, and coercion. In Proceedings of ESCOL 99, Anastasia Riehl and Rebecca Daly (eds.), 173-190. Ithaca, NY: Cornell University Linguistics Students Association.

2000b Genitives, relational nouns, and the argument-modifier distinction. In ZAS Papers in Linguistics 17, Cathrine Fabricius-Hansen, Ewald Lang, and Claudia Maienborn (eds.), 177201. Berlin: Zentrum für Allgemeine Sprachwissenschaft, Sprachtypologie und Universalienforschung.

2001 Some puzzles of predicate possessives. In Perspectives on Semantics, Pragmatics and Discourse: A Festschrift for Ferenc Kiefer, István Kenesei and R. M. Harnish (eds.), 91-117. Amsterdam: John Benjamins Publishing Company.

Pustejovsky, James

1993 Type coercion and lexical selection. In Semantics and the Lexicon, J. Pustejovsky (ed.), 7394. Dordrecht: Kluwer.

1995 The Generative Lexicon. The MIT Press.

Rakhilina, Ekaterina

2001 Pokazateli posessivnosti i ix funkcii v russkom jazyke [Indicators of possessivity and their function in the Russian language]. In Issledovanija po jazykoznaniju, S. Šbik (ed.), 197207. St. Petersburg: St. Petersburg University Press. 
Rappaport, Gilbert

1998 The Slavic noun phrase. Position paper for Comparative Slavic Morphosyntax. Available at: http://www.indiana.edu/ slavconf/ linguistics/download.html [1999, Jan. 4].

Schoorlemmer, Maaike

1995 Participial passive and aspect in Russian. Ph.D. dissertation, Utrecht: OTS (Utrecht Institute of Linguistics).

Siegel, Muffy

1976 Capturing the Russian adjective. In Montague Grammar, B. Partee (ed.), 293-309. New York: Academic Press.

Stockwell, R. P., P. Schachter, and B. H. Partee

1973 The Major Syntactic Structures of English. New York: Holt, Rinehart and Winston.

Storto, Gianluca

2000 On the structure of indefinite possessives. In SALT X: Proceedings of the Tenth Conference on Semantics and Linguistic Theory 2000, Brendan Jackson and Tanya Matthews (eds.), Ithaca, N.Y.: CLC Publications, Department of Linguistics, Cornell University.

Strauss, Uri

2002 Individual-denoting and property-denoting possessives. Paper presented at the Workshop on the Syntax and Semantics of Possessives, University of Massachusetts, May 2002.

Szabolcsi, Anna

1994 The Noun Phrase. In The Syntactic Structure of Hungarian, F. Kiefer and K. É. Kiss (eds.), 179-275. (Syntax and Semantics 27.) New York: Academic Press.

Vikner, Carl, and Per Anker Jensen

2002 A semantic analysis of the English genitive. Interaction of lexical and formal semantics. Studia Linguistica 56:191-226. Williams, Edwin

1981 Argument structure and morphology. The Linguistic Review 1: 81-114.

1983 Semantic vs. syntactic categories. Linguistics and Philosophy 6: 423-424. 